\title{
BROOKHISUEN
}

NATIONAL LABORATORY

BNL-113706-2017-CP

\section{CdxZn1-xTeySe1-y (CZTS): An Emerging High-Performance Gamma-Ray Detector}

\author{
Utpal N. Roy
}

Presented at the Nuclear Security Applications and Development Program Review Meeting (NSARD2017)

Brookhaven National Laboratory, Upton, NY

NNSA North Las Vegas Facility, Las Vegas, NV

April 4-6, 2017

April 2017

Nonproliferation and National Security Department

Brookhaven National Laboratory

\section{U.S. Department of Energy \\ USDOE National Nuclear Security Administration (NNSA), Office of Defense Nuclear Nonproliferation (NA-20)}




\section{DISCLAIMER}

This report was prepared as an account of work sponsored by an agency of the United States Government. Neither the United States Government nor any agency thereof, nor any of their employees, nor any of their contractors, subcontractors, or their employees, makes any warranty, express or implied, or assumes any legal liability or responsibility for the accuracy, completeness, or any third party's use or the results of such use of any information, apparatus, product, or process disclosed, or represents that its use would not infringe privately owned rights. Reference herein to any specific commercial product, process, or service by trade name, trademark, manufacturer, or otherwise, does not necessarily constitute or imply its endorsement, recommendation, or favoring by the United States Government or any agency thereof or its contractors or subcontractors. The views and opinions of authors expressed herein do not necessarily state or reflect those of the United States Government or any agency thereof. 
Defense Nuclear Nonproliferation Research \& Development

\section{Nuclear Security Applications \\ Research \& Development Portfolio Review \\ NSARD 2017}

$\mathrm{Cd}_{\mathrm{x}} \mathrm{Zn}_{1-\mathrm{x}} \mathrm{Te}_{\mathrm{y}} \mathrm{Se}_{1-y}(\mathrm{CZTS}):$ An Emerging High-
Performance Gamma-Ray Detector

Utpal N Roy

Brookhaven National Laboratory

April $5^{\text {th }}, 2017$ Notice: This manuscript has been authored by employees of Brookhaven Science Associates, LLC under Contract No. DE- SC0012704 with the U.S. Department of Energy. The publisher by accepting the manuscript for publication acknowledges that the United States Government retains a non-exclusive, paid-up, irrevocable, world-wide license to publish or reproduce the published form of this manuscript, or allow others to do so, for United States Government purposes. This preprint is intended for publication in a journal or proceedings. Since changes may be made before publication, it may not be cited or reproduced without the author's permission. 


\section{Research team}

Participating Laboratories:

Brookhaven National Laboratory (BNL)

Lawrence Livermore National Laboratory (LLNL)

Co-PIs:

U. N. Roy and V. Lordi

BNL Supporting Researchers:

G. S. Camarda, G. Yang, Y. Cui, R. Gul, A. Hossain and P. Vanier

LLNL Supporting Researchers:

J. Varley, A. Samanta

Supporting Institutions:

R. B. James, Savannah River National Laboratory (SRNL)

J. Franc, J. Zazvorka and V. Dedic, Institute of Physics of Charles University, MFF, Ke Karlovu 5, Prague 2, Czech Republic. 


\section{Project overview}

Today, cadmium zinc telluride (CZT) is the most advanced roomtemperature semiconductor material for gamma-ray detection.

$\square$ However, CZT suffers from 3 major detrimental defects

- Non-unity segregation of Zn

- Crystal defect (sub-grain boundary) network

- High concentrations of Te inclusions/precipitates
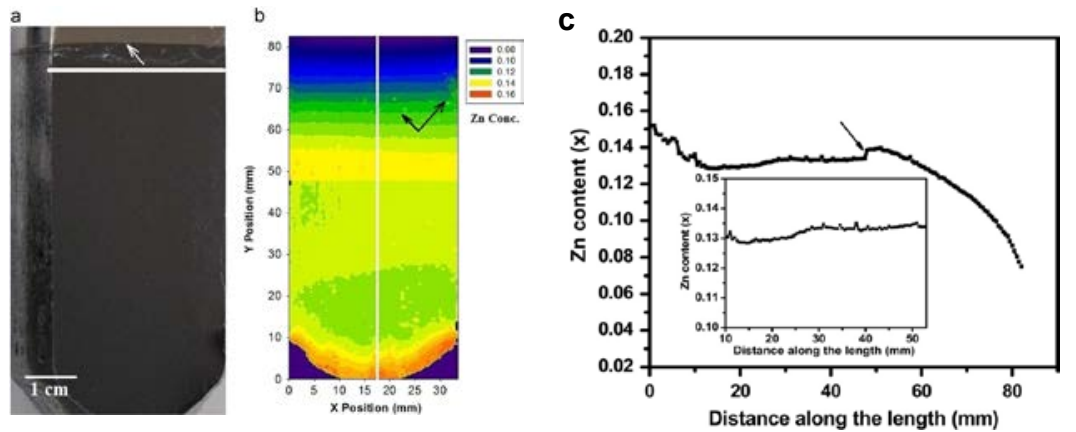

(a) THM-grown CZT ingot cut along the length, (b) $\mathrm{Zn}$ concentration mapping and (c) Zn concentration along the length of the ingot.

Roy et al. J. Crystal Growth 347 (2012) 53.

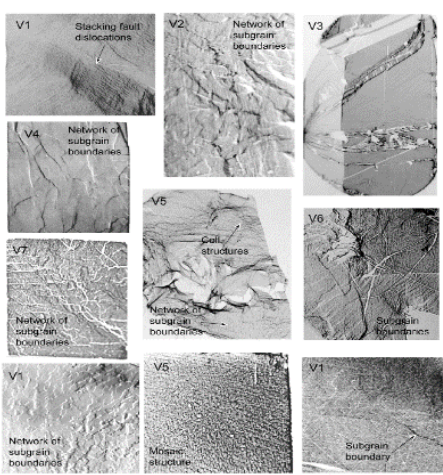

$X$-Ray diffraction topography images showing $\sim 1 \mathrm{~cm}^{2}$ areas of detector-grade CZT samples supplied by seven different vendors.

A. E. Bolotnikov et al. J. Cryst. Growth 379 (2013) 46.

- These issues cause low yield and high cost of CZT radiation detectors, limiting their applications.

- Researchers have tried to solve the issues by improving the crystal growth process and post-growth annealing, but have not mitigated all disadvantages. 


\section{Project goal and deliverables}

The goal of the proposed project is to develop as-grown CZTS radiation detectors with high compositional uniformity, better performance, higher yield and lower cost than today's CZT.

Deliverables:

$\square$ Growth of eight CZTS ingots per year.

$\checkmark$ Characterization of the as-grown ingots:

- X-ray topography, IR microscopy, compositional uniformity by EDS and $X$-ray fluorescence, photoluminescence (PL), DLTS, I-V, and chargetransport characterization.

$\square$ Detector fabrication and test.

$\square$ Compute maps of band gap and band edge positions for CZTS alloy across the composition range of $\mathrm{Zn}$ and Se.

$\square$ Compute thermodynamic stability and phase separation of CZTS alloy as a function of composition and temperature.

$\square$ Compute accurate prediction of defect levels across alloy compositions 


\section{Growth and characterization}

$\square$ CZTS ingots were grown by traveling heater method (THM) as well as vertical Bridgman Method (BM).

- $6 \mathrm{~N}$ purity CdZnTe and CdSe were used for synthesis of the CZTS compound.

- 6N purity Te was used as solvent for THM growth.

Although BM technique is being used for crystal growth, our main thrust is THM growth of CZTS for its following advantages:

- Low-temperature growth

- Less chance of incorporation of impurities from the crucible during growth

- Less/no chance of ampoule explosion

- Enhanced purity of the ingot

- Fewer defects due to the lower growth temperature

$\square$ Crystals were cut and polished for various characterizations and detector fabrication and testing. 


\section{CZTS ingots}

$\square$ We are focusing on THM-growth of 2-in diameter CZTS ingots with different elemental compositions:

$$
\mathrm{Cd}_{0.9} Z n_{0.1} \mathrm{Te}_{0.93} \mathrm{Se}_{0.07} \text { ingots: }
$$

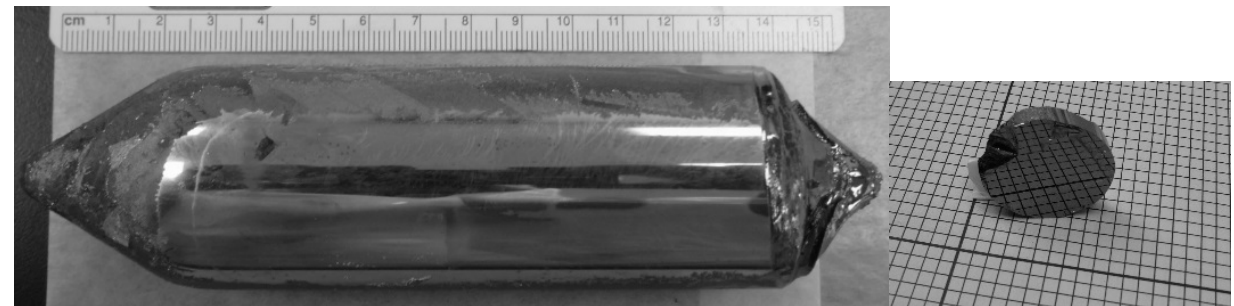

40-mm diameter ingot grown by BM (undoped).

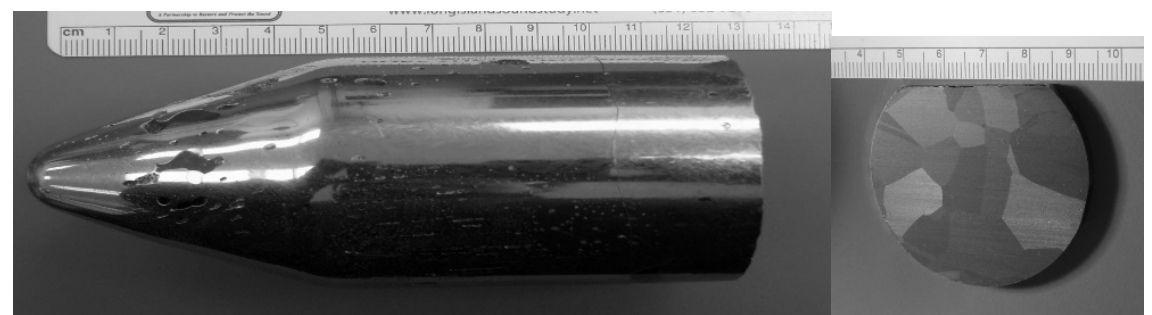

In-doped 52-mm diameter ingot grown by THM (fast cooled ingot).

$$
\mathrm{Cd}_{0.9} \mathrm{Zn}_{0.1} T \mathrm{e}_{0.96} \mathrm{Se}_{0.04} \text { ingots: }
$$

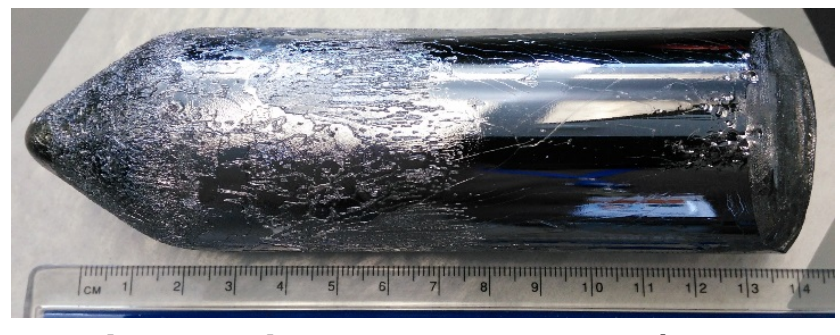

40-mm diameter ingot grown by BM (undoped).

$\mathrm{Cd}_{0.9} \mathrm{Zn}_{0.1} \mathrm{Te}_{0.98} \mathrm{Se}_{0.02}$ ingots:

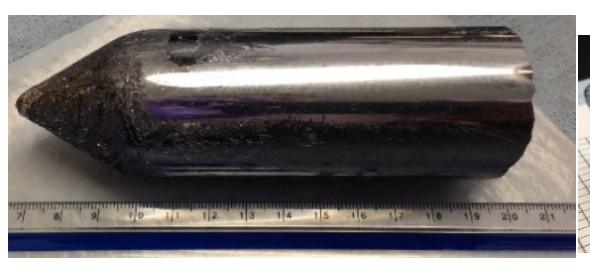

40-mm diameter ingot grown by BM (undoped). Office of Defense Nuclear Nonproliferation $R \& D$

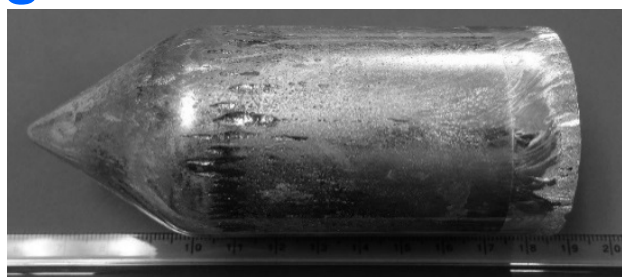

In-doped 52-mm diameter ingot grown by THM.

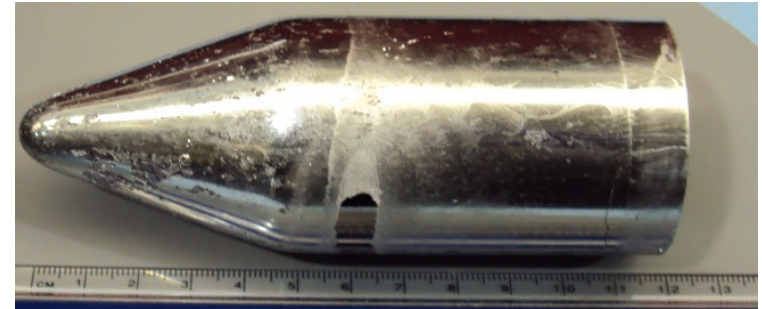

In-doped 52-mm diameter ingot grown by THM.

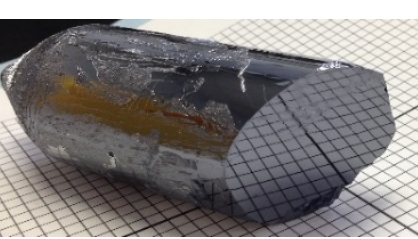
Unclassified 
THM growth is highly sensitive to growth parameters.

i. Width of Te-rich solution zone

ii. Growth temperature

iii. Temperature gradient near the growth interface
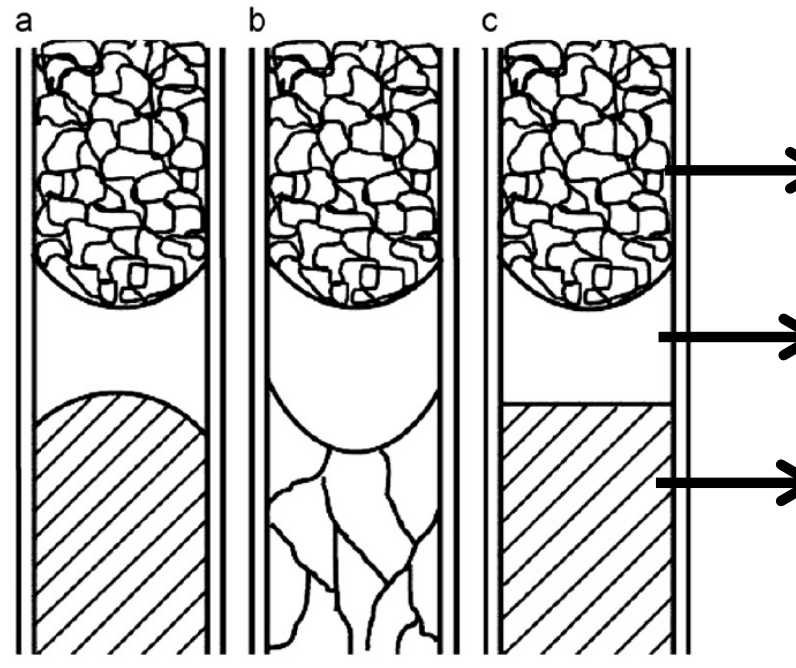

Schematic of growth interface shape

A) convex, B) concave and C) flat.
Feed material

Te-rich CZTS molten zone

Grown ingot

Convex and flat growth interfaces are favorable for growth of large grain and single crystalline ingots.

Flat interfaces are desired for seeded growth. 


\section{Growth interface (THM)}

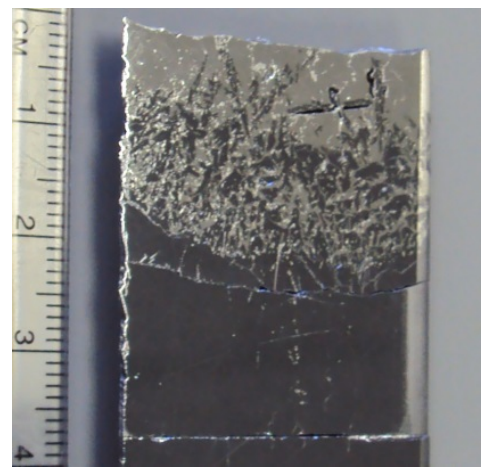

Concave interface of 52- $\mathrm{mm}$ diameter $\mathrm{Cd}_{0.9} Z n_{0.1} T e_{0.93} \mathrm{Se}_{0.07}$ ingot grown by THM.

The very first CZTS ingot.

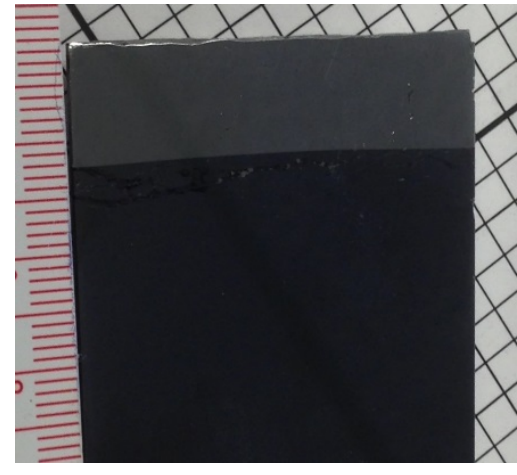

Slightly convex nearly flat interface of 52-mm diameter $\mathrm{Cd}_{0.9} \mathrm{Zn}_{0.1} \mathrm{Te}_{0.98} \mathrm{Se}_{0.02}$ ingot grown by THM.

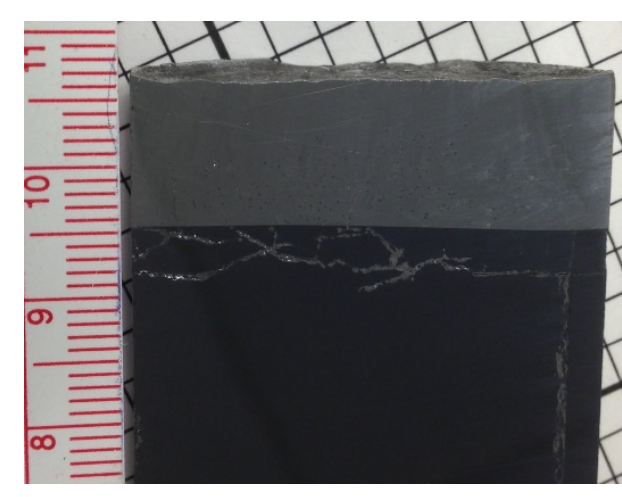

Slightly convex nearly flat interface of 52-mm diameter $\mathrm{Cd}_{0.9} \mathrm{Zn}_{0.1} \mathrm{Te}_{0.96} \mathrm{Se}_{0.04}$ ingot grown by THM.

Since our goal is seeded growth, we are focusing on achieving slightly convex and nearly flat growth interface. 


\section{Compositional distributions in CZTS}
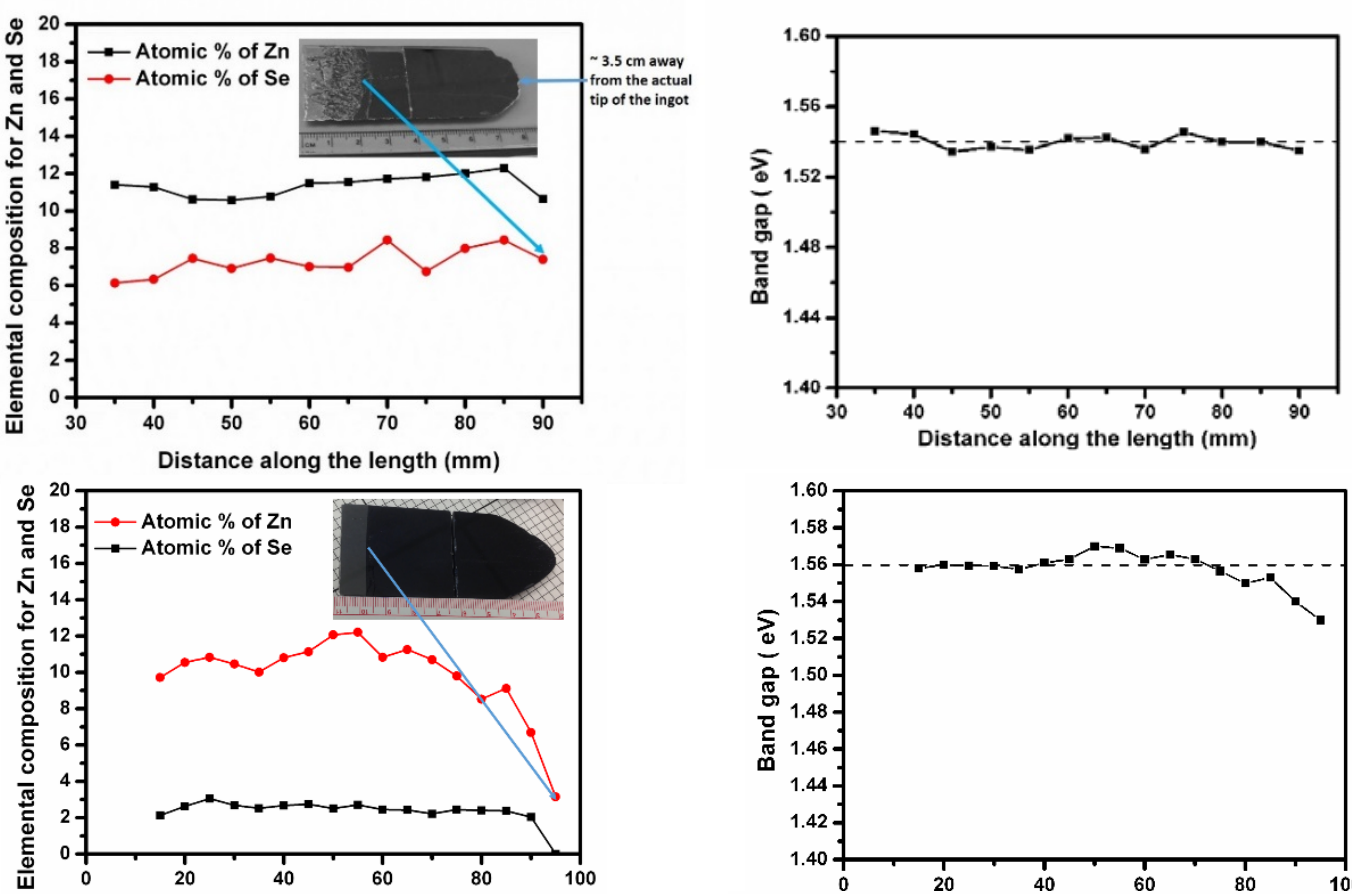

Distance along the length $(\mathrm{mm})$
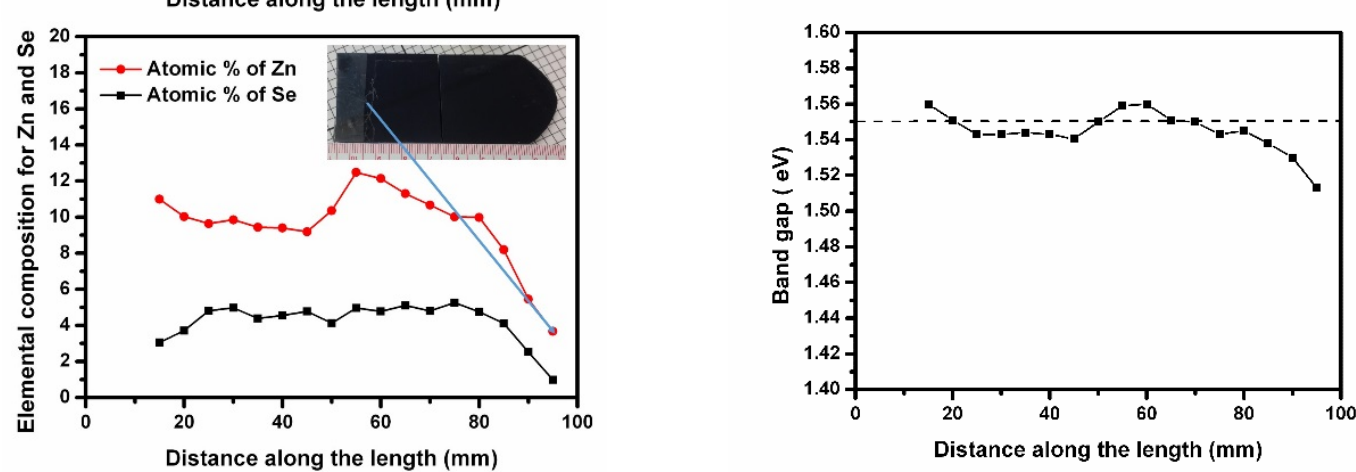

Composition of Zn and Se is fairly uniform throughout the ingot for $\mathrm{Cd}_{0.9} \mathrm{Zn}_{0.1} \mathrm{Te}_{0.93} \mathrm{Se}_{0.07}$. Especially the calculated band gap.

For $2 \%$ and $4 \%$ Se composition,

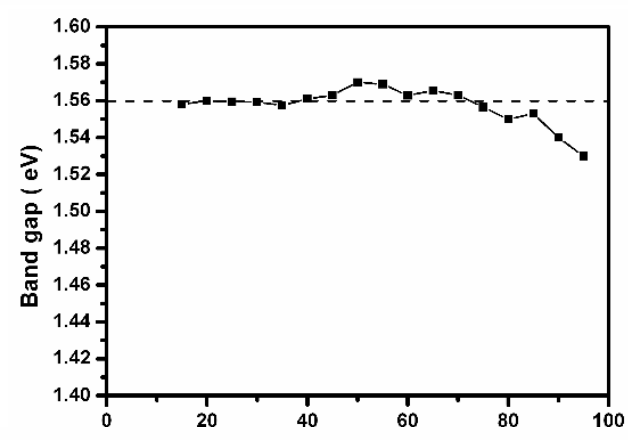

the band gap of the ingots is fairly uniform within the experimental accuracy. It only decreases in a narrow region $(<1 \mathrm{~cm})$ near the interface.

$\sim 90 \%$ of the ingot shows uniform band gap for both 2 and $4 \%$ Se composition).

On the contrary, for THM grown CZT, only about one third of the ingot shows uniform composition.

$\mathrm{Zn}$ and Se composition and the calculated band gap along the length of the THM-grown $C d_{0.9} Z n_{0.1} T e_{0.93} S_{0.07}, C d_{0.9} Z n_{0.1} T e_{0.98} S e_{0.02}$ and $C d_{0.9} Z n_{0.1} T e_{0.96} S e_{0.04}$ ingots: from top to bottom. 


\section{X-ray topographic analyses}
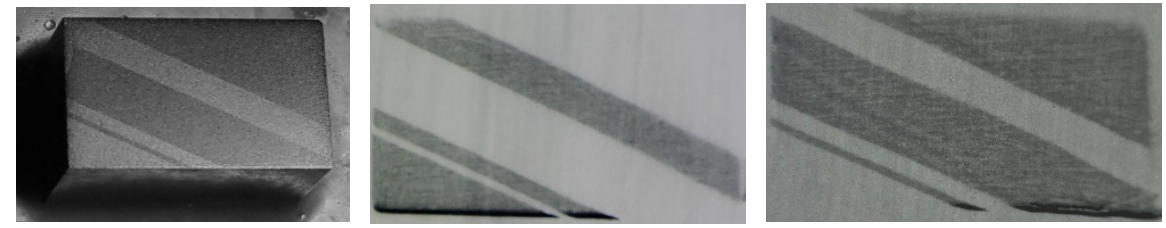

Optical photograph of lapped, and X-ray topographic pictures of Bridgman grown $\mathrm{Cd}_{0.9} \mathrm{Zn}_{0.1} \mathrm{Te}_{0.93} \mathrm{Se}_{0.07}$ sample of dimensions $5 \times 6 \times 11 \mathrm{~mm}^{3}$
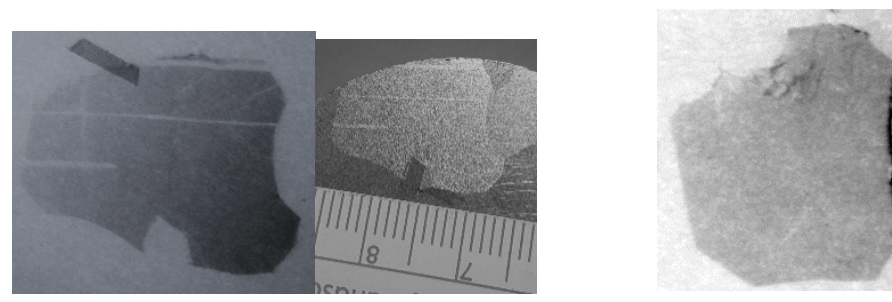

a)-c): X-ray topographic pictures of THM-grown

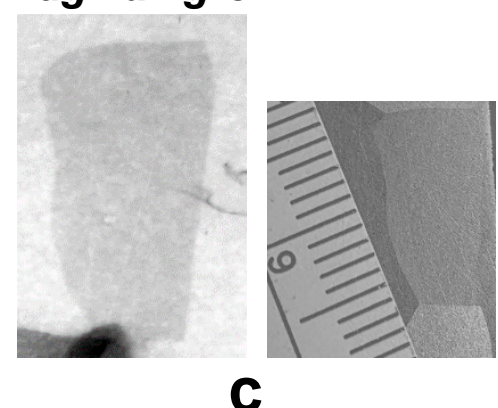

C optical photography of the grains.

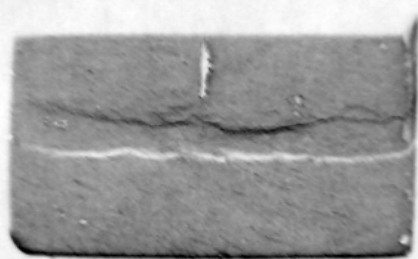

a

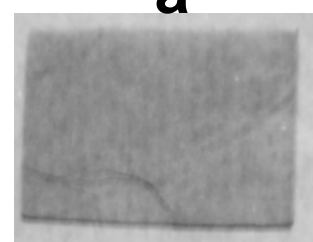

a

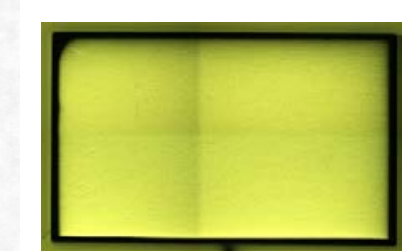

b

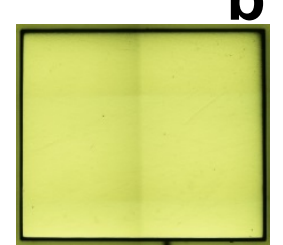

b

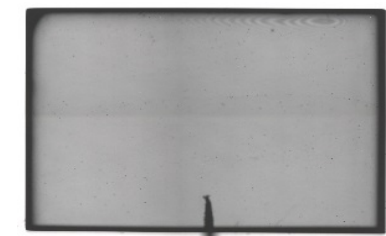

C

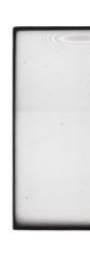

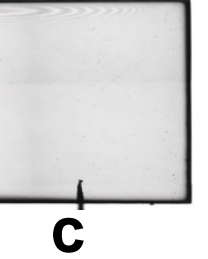
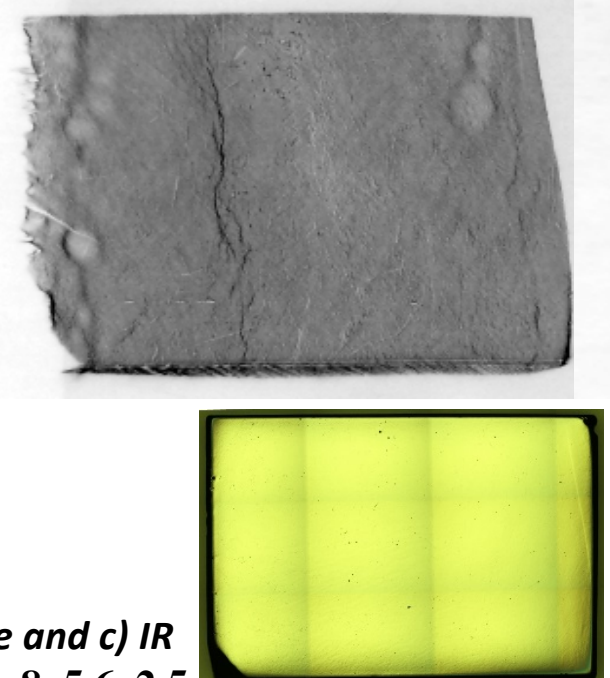

Higher Se

concentration is more effective in arresting sub-grain boundary. No subgrain boundary network was evidenced.

a) X-ray topographic, b) photograph of the polished sample in reflection mode and c) IR transmission picture of a THM-grown $\mathrm{Cd}_{0.9} \mathrm{Zn}_{0.1} \mathrm{Te}_{0.98} \mathrm{Se}_{0.02}$ sample. Dimensions: 8x5.6x2.5 $\mathrm{mm}^{3}$ and $8.2 \times 7 \times 1.55 \mathrm{~mm}^{3}$. Office of Defense Nuclear Nonproliferation R\&D Unclassified

$X$-ray topographic picture and photograph of the polished sample. The surface area is $\sim 15 \times 10 \mathrm{~mm}^{2}$. 


\section{Concentrations and size distribution of Te inclusions in CZTS}

For both Bridgman and THM grown $C d_{0.9} \mathrm{Zn}_{0.1} \mathrm{Te}_{0.93} S e_{0.07}$ ingots, concentrations of Te inclusions/precipitates were found 8-9 times lower than in standard CZT.

Evaluation of size distribution of Te inclusions/precipitates for $C d_{0.9} Z n_{0.1} T e_{0.98} S e_{0.02}$ and $C d_{0.9} Z_{0.1} T e_{0.96} S e_{0.04}$ ingots will be performed soon. 


\section{Unclassified
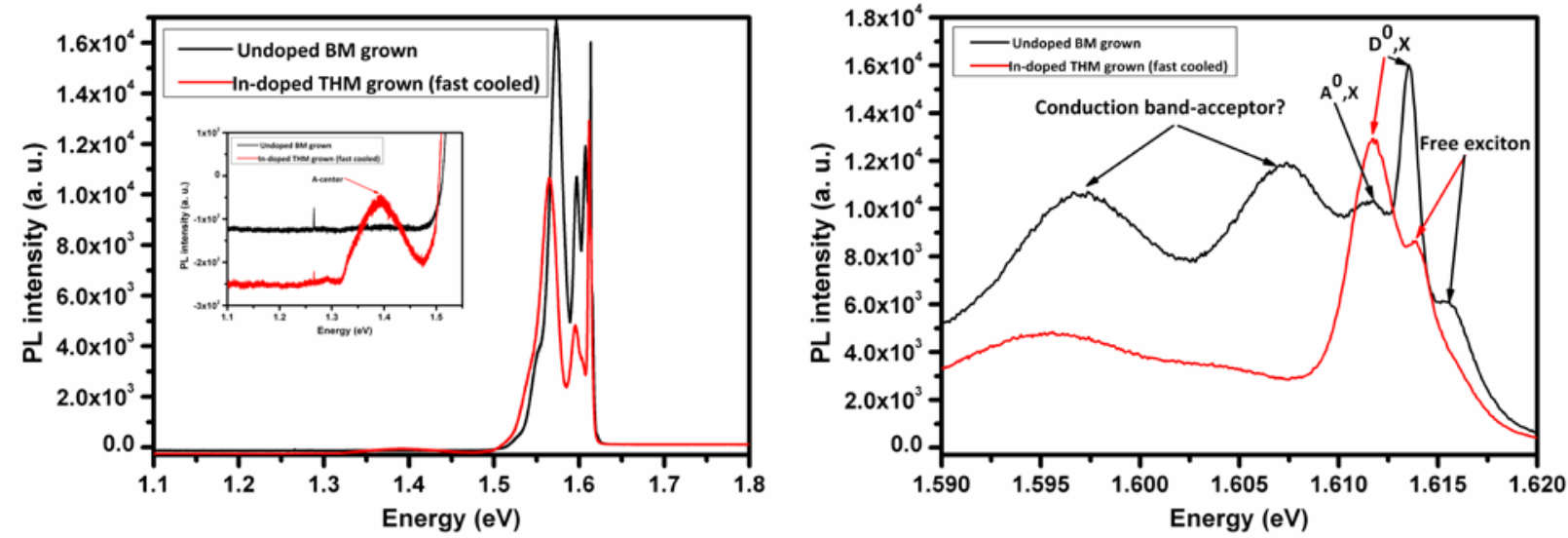

PL-spectrum: BM-grown un-doped and THM-grown In-doped $\mathrm{Cd}_{0.9} \mathrm{Zn}_{0.1} \mathrm{Te}_{0.93} \mathrm{Se}_{0.07}$ at $4.2 \mathrm{~K}$.

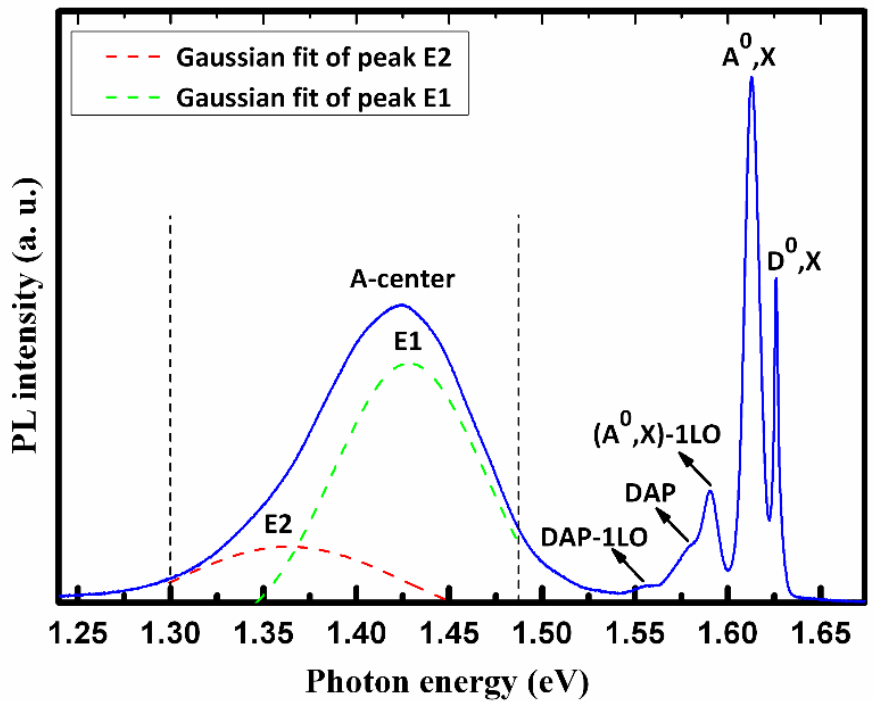

A-centers seem to be reduced with increased Se concentrations.

PL-spectrum: THM-grown In-doped $\mathrm{Cd}_{0.9} \mathrm{Zn}_{0.1} \mathrm{Te}_{0.98} \mathrm{Se}_{0.02}$ at $7 \mathrm{~K}$. 


\section{Roles of Se}

- Strong influence in modifying Zn segregation coefficient: better compositional homogeneity with increased Se concentration.

- Effective solution hardening in arresting sub-grain boundaries and their network with increased Se content.

- Decreased Te-inclusion/precipitate concentration with increased Se content.

- Decrease of A-center with increased Se content. 


\section{Unclassified \\ Resistivity mapping of CZTS 2-inch wafer}

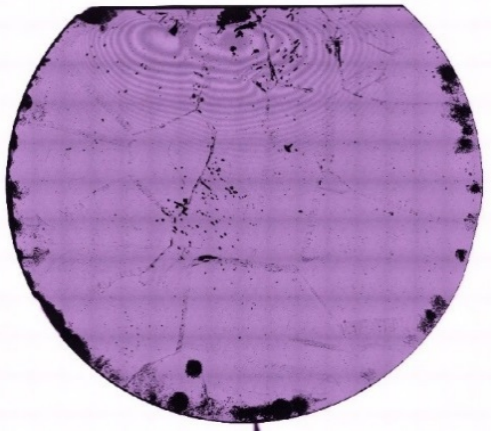

a

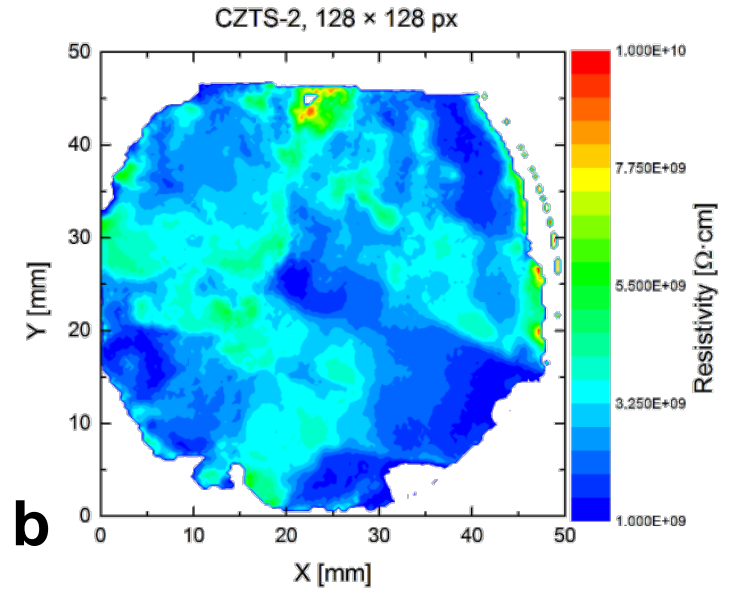

(a) IR transmission image; and (b) resistivity map at room temperature of 4.2-mm thick $\mathrm{Cd}_{0.9} \mathrm{Zn}_{0.1} \mathrm{Te}_{0.93} \mathrm{Se}_{0.07}$ wafer grown by THM.

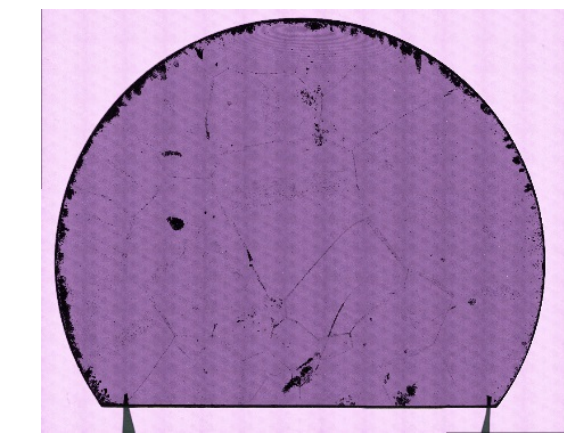

$\mathbf{a}$

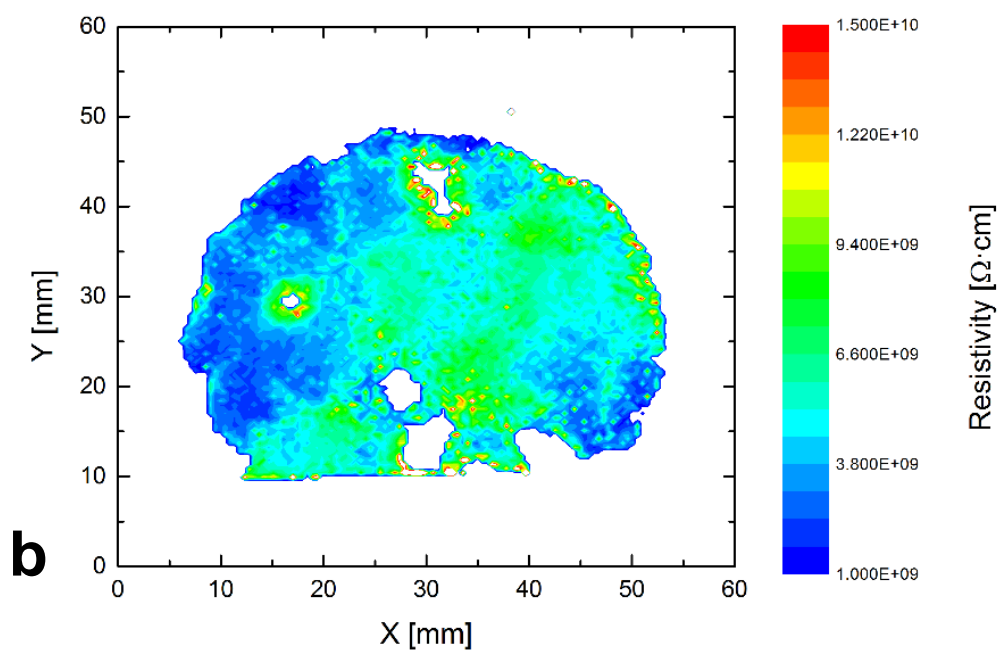

(a) IR transmission image; and (b) resistivity map at room temperature of 3.3-mm thick $\mathrm{Cd}_{0.9} \mathrm{Zn}_{0.1} \mathrm{Te}_{0.98} \mathrm{Se}_{0.02}$ wafer grown by $\mathrm{THM}$. 


\section{PL map of CZTS 2-inch wafer}
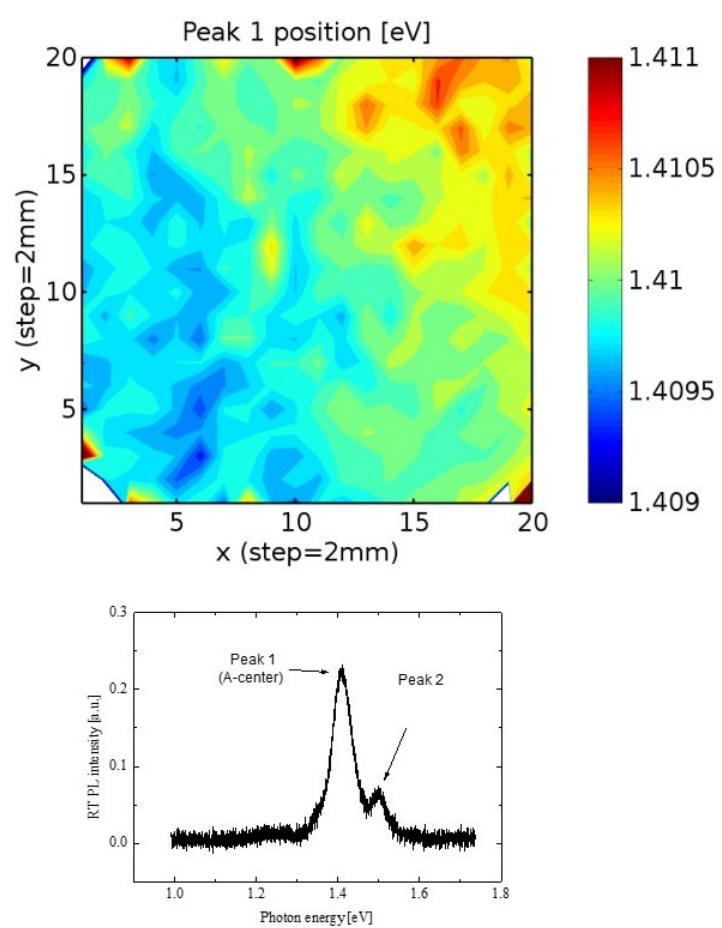

Room temperature photoluminescence ( $P L)$ map of $\mathrm{Cd}_{0.9} Z_{0.1} \mathrm{Te}_{0.93} \mathrm{Se}_{0.07}$ two inch wafer grown by THM. The map area is $4 \times 4 \mathrm{~cm}^{2}$. Step size $2 \mathrm{~mm}$.

Variation of the peak energy (peak 1) over the entire scan area, $\Delta E$ is 2 meV, thus the composition and band gap are highly uniform over the $4 \times 4 \mathrm{~cm}^{2}$ area.
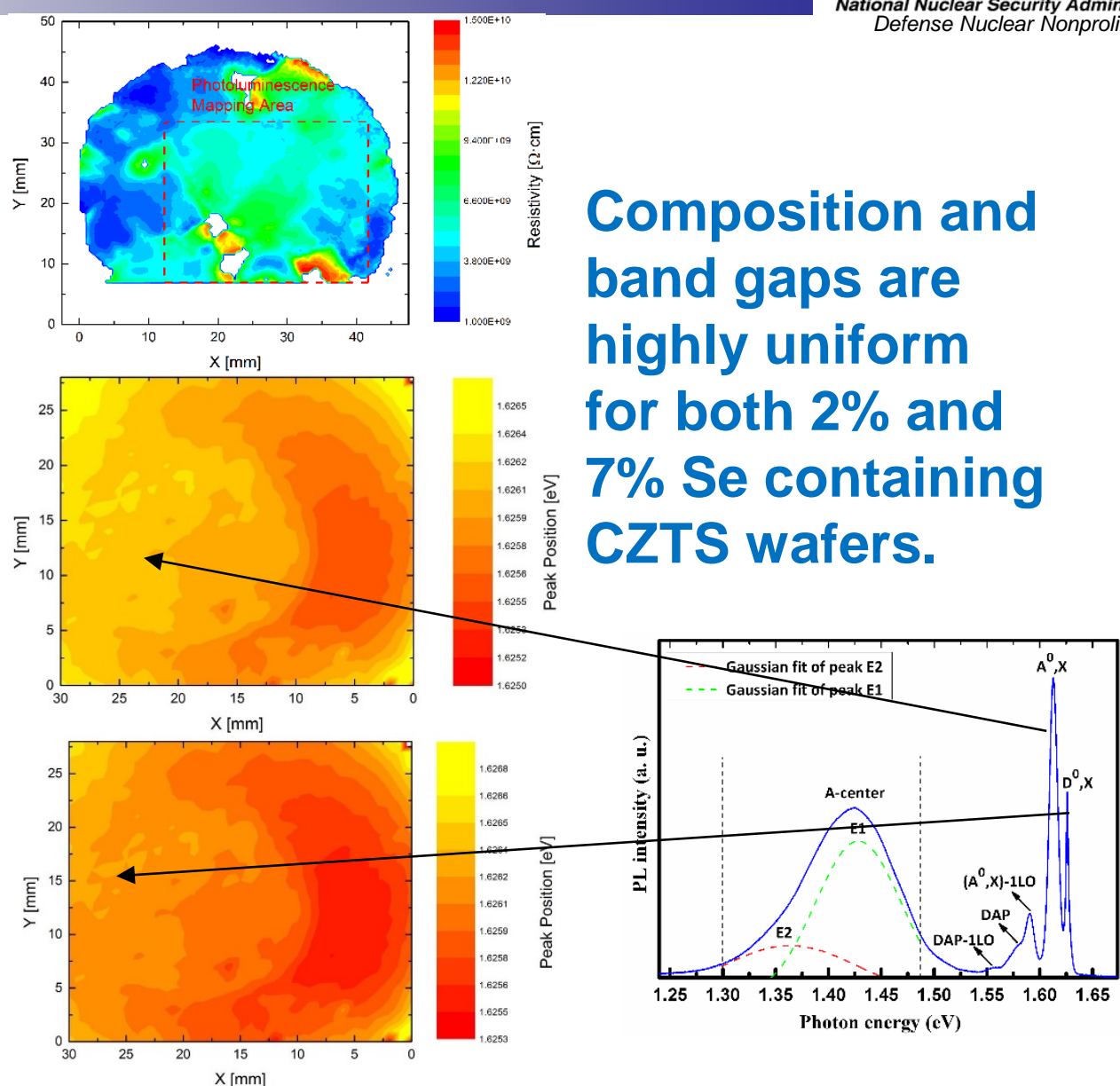

Low temperature (7K) photoluminescence $(P L)$ map of $\mathrm{Cd}_{0.9} \mathrm{Zn}_{0.1} \mathrm{Te}_{0.98} \mathrm{Se} \mathrm{e}_{0.02}$ two inch wafer grown by THM. The map area is $-2.8 \times 3 \mathrm{~cm}^{2}$. Step size $1 \mathrm{~mm}$.

Variation of the peak energy $\left(A^{0}, X\right.$ and $\left.D^{0}, X\right)$ over the entire scan area, $\Delta E$ is $\sim 1.5 \mathrm{meV}$, thus the composition and band gap are highly uniform over the $2.8 \times 3 \mathrm{~cm}^{2}$ area.

Unclassified
Composition and band gaps are highly uniform for both $2 \%$ and $7 \%$ Se containing CZTS wafers. 

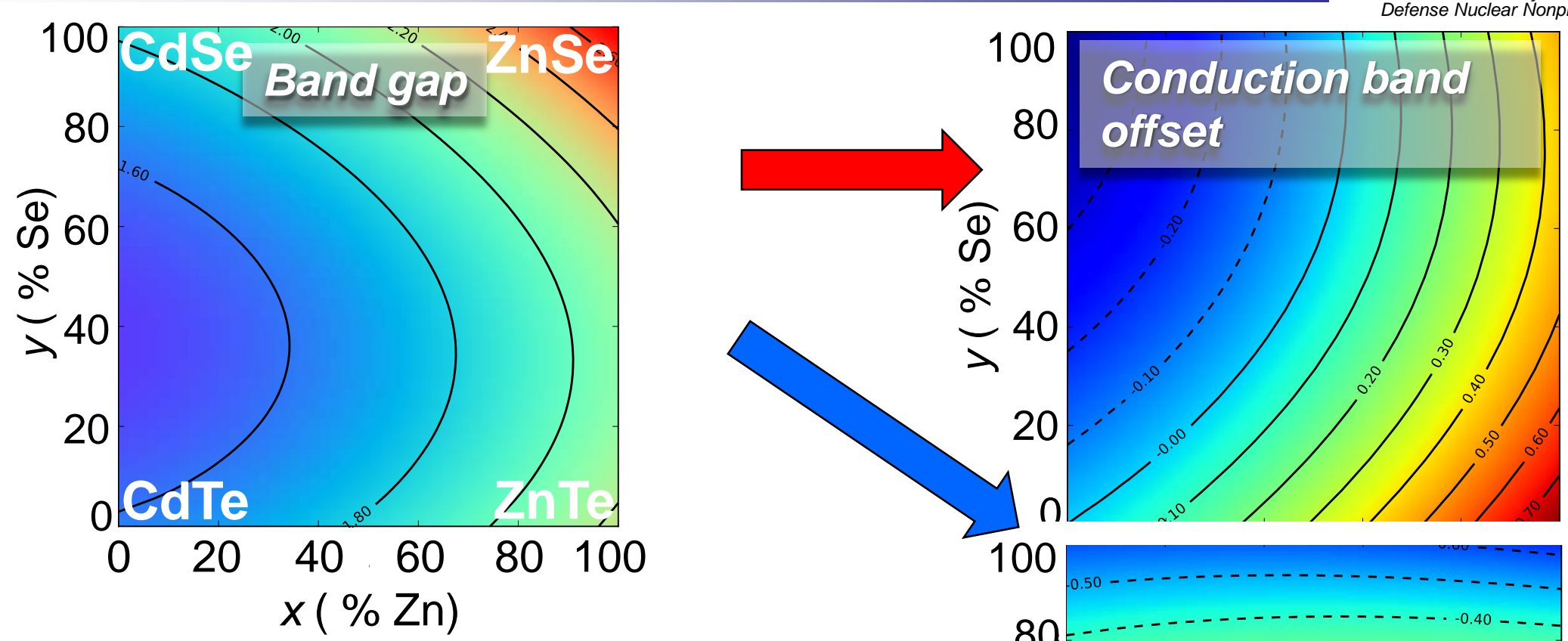

- Computed absolute band edge energies across composition range helps choose best compositions

- Band edges contribute to intrinsic resistivity, dopant compensation and impurity trap levels (also next slide)

- Band edge engineering can also help design optimal contacts

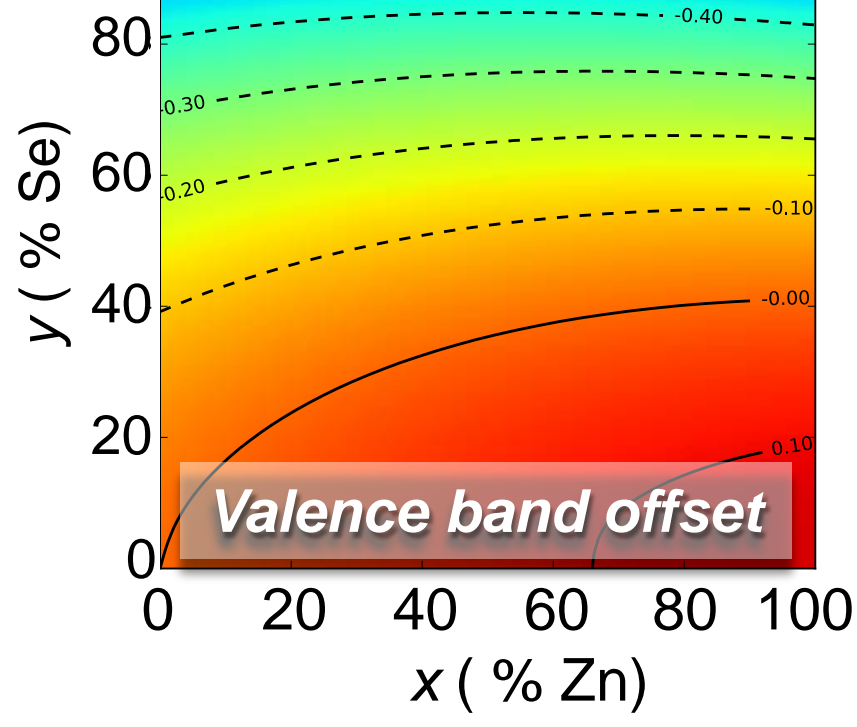




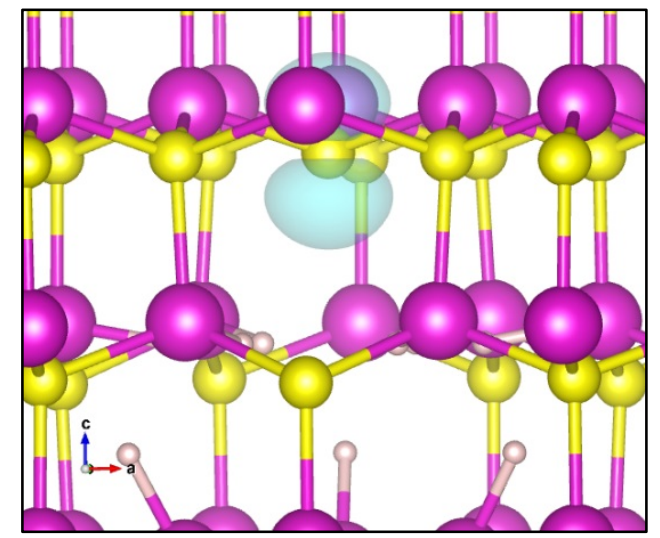

Dangling bond analysis

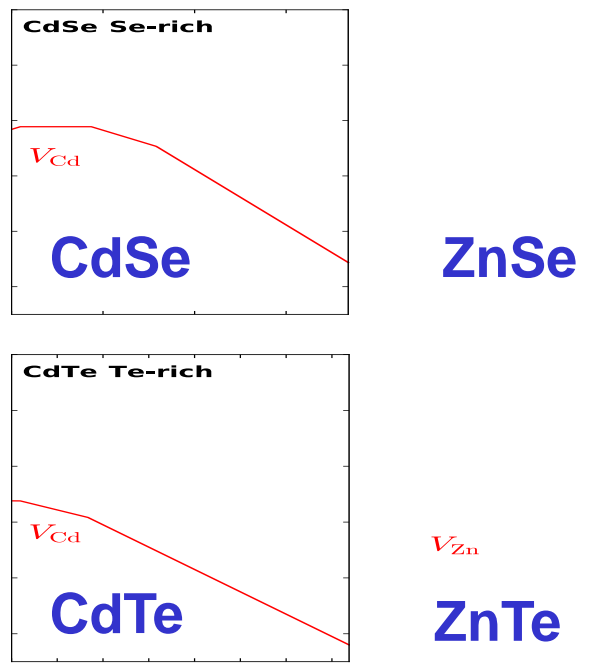

Point defect properties of end-point binaries

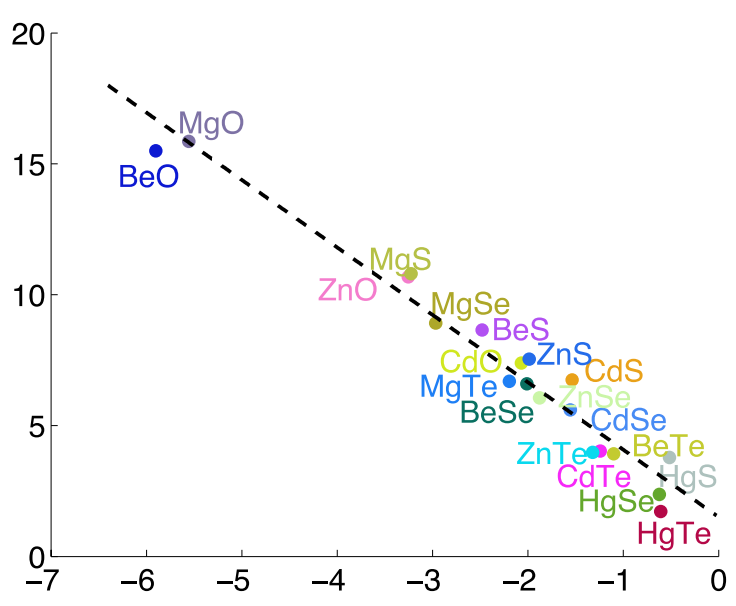

Descriptors for interpolation using machine learning

- Various computational machinery developed for accurate prediction of defect levels across alloy compositions

- Dangling bonds, band edge positions, machine learning

- Allows optimization of dopants with composition and comparison to DLTS experiments for validation

- Applied to cation vacancies, other defects/impurities on-going 


\section{Charge transport properties of THM-grown $C d_{0.9} Z n_{0.1} T e_{0.98} S e_{0.02}$}

Charge collection versus applied bias voltage

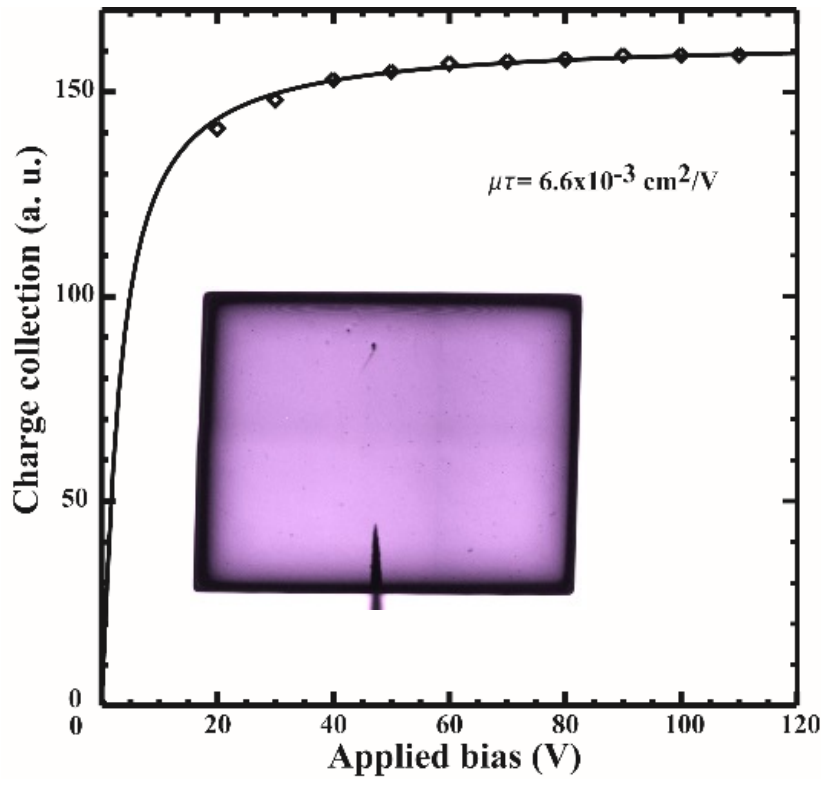

- $\quad{ }^{241} \mathrm{Am}$ source

- Planar detector: $6.65 \times 5.75 \times 1.86 \mathrm{~mm}^{3}$

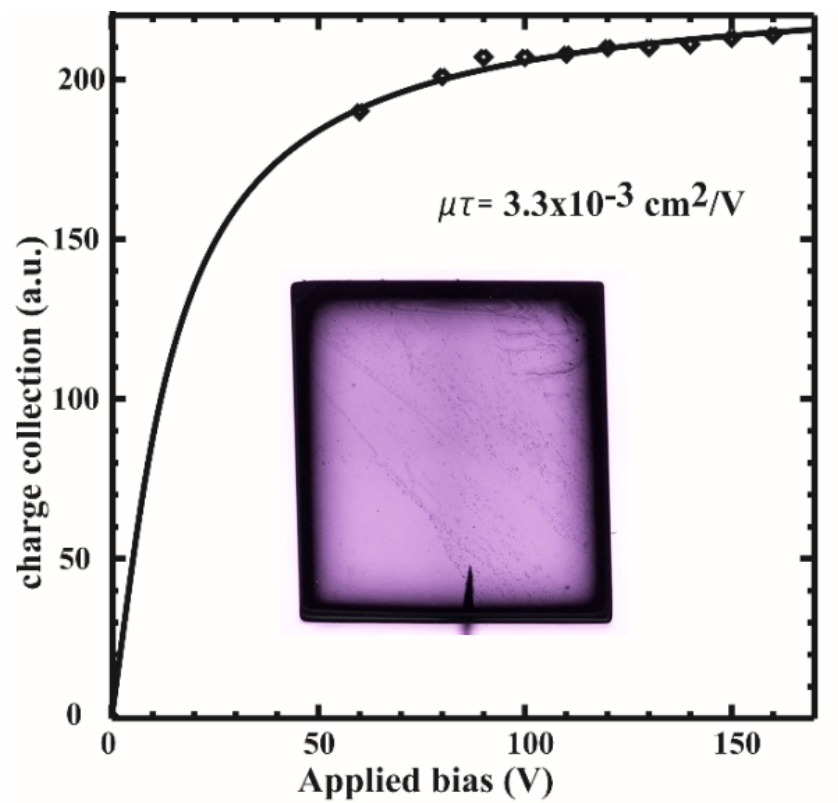

- ${ }^{241} \mathrm{Am}$ source

- Planar detector: $5.65 \times 5.18 \times 2.8 \mathrm{~mm}^{3}$

- Sample with more Te-inclusions/precipitations

In general the $\mu$ r product varies between $4.5-6 \times 10^{-3} \mathrm{~cm}^{2} / \mathrm{V}$. 


\section{Unclassified}

\section{Detector response of THM-grown $C d_{0.9} Z_{0.1} T e_{0.98} S e_{0.02}$}
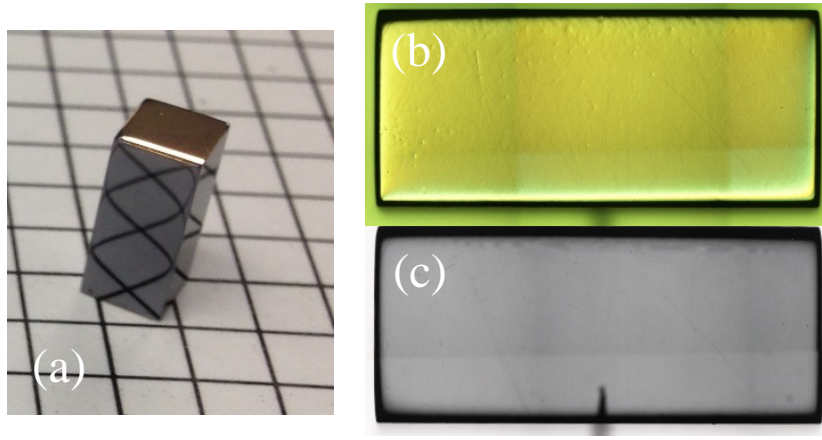

(a) Picture of the detector: $4.4 \times 4.4 \times 10 \mathrm{~mm}^{3}$

(b) Reflection mode microscopic scan

(c) IR transmission image

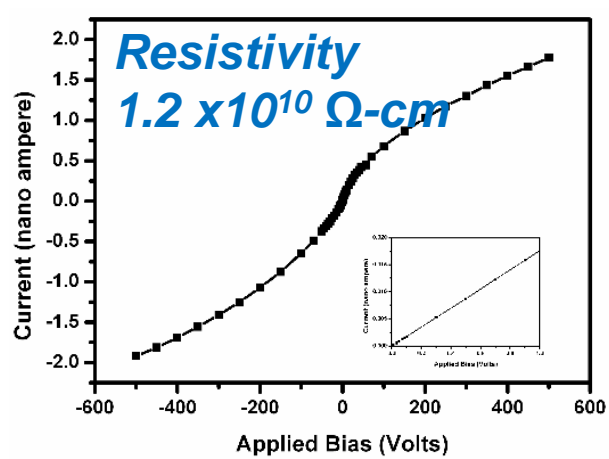

I-V characteristics at room temperature. Inset: I-V for 0-1V.

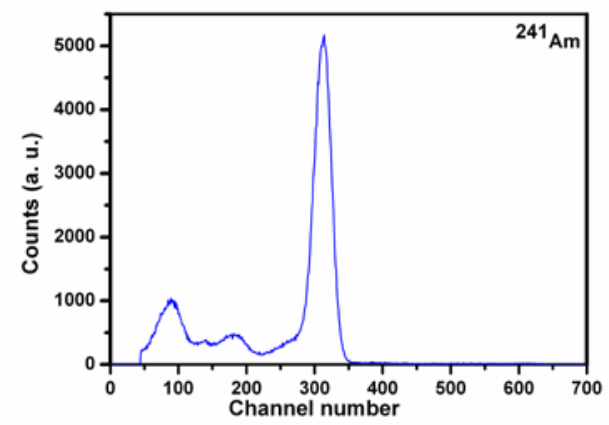

Bias voltage: $1800 \mathrm{~V}$

Shaping time 3 micro sec.

Device response of the very first virtual Frisch grid detector
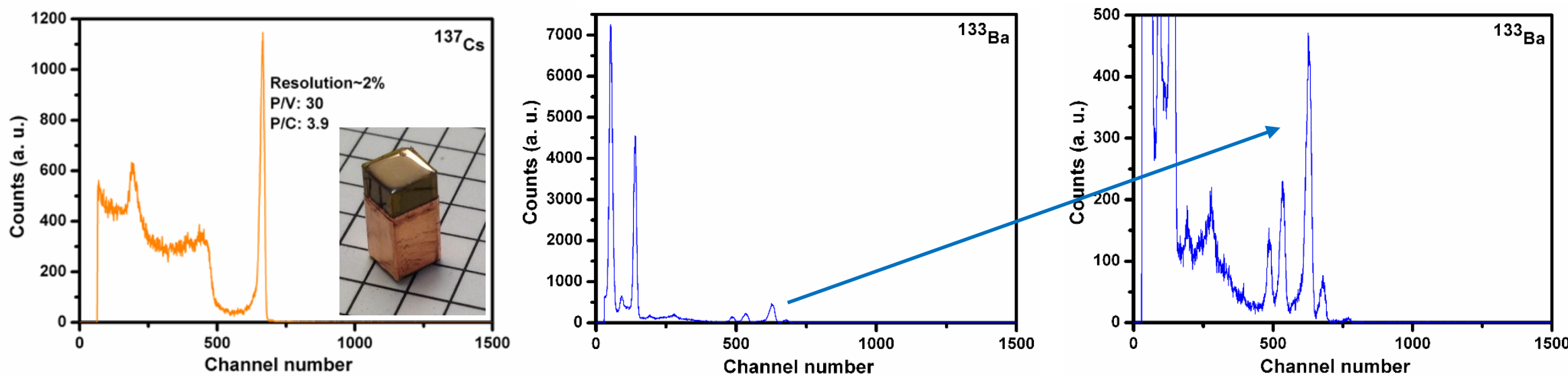

Bias voltage: $2300 \mathrm{~V}$, (Frisch grid $7 \mathrm{~mm}$ long) Shaping time $10 \mu \mathrm{s}$.

Bias voltage: 2300V, Shaping time $6 \mu$ s.

\section{All the spectra are as-measured without any correction technique.}




\section{Unclassified}

Detector response of THM-grown

\section{$C d_{0.9} Z n_{0.1} T e_{0.98} S e_{0.02}$}

Device response of the very first virtual Frisch grid detector (cont'd)
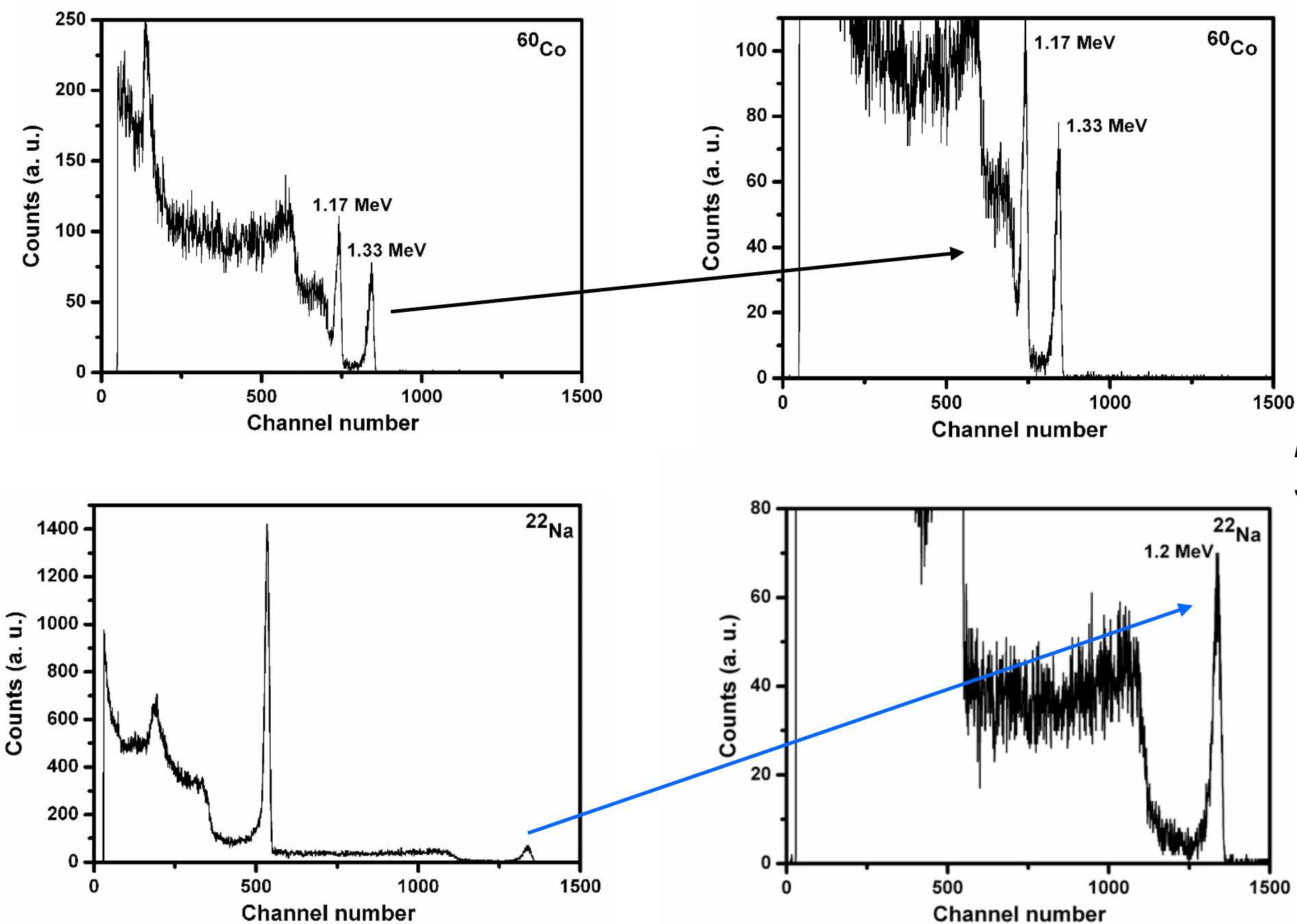

HV: $-2300 \mathrm{~V}$,

Shaping time $10 \mu \mathrm{s}$

All the spectra are as-measured without any correction technique. 


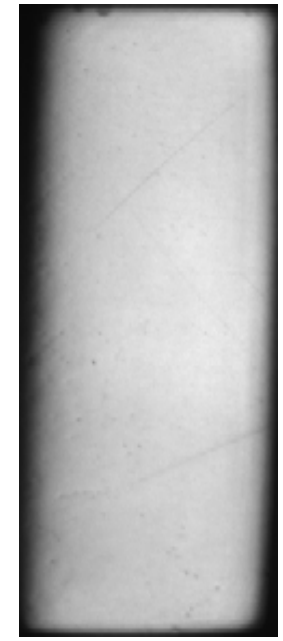

a

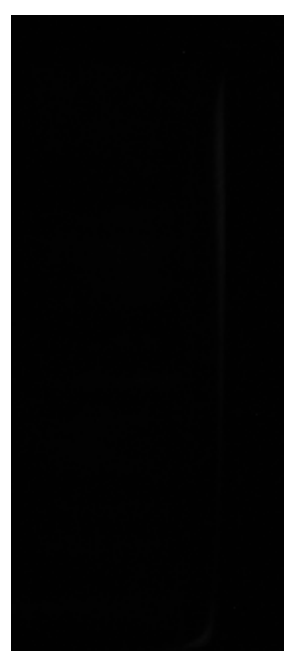

b

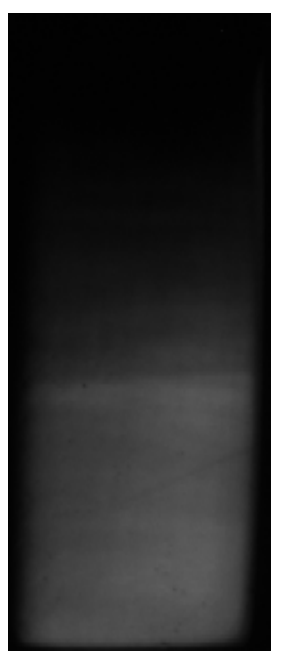

C

IR transmission image of the detector

a) Under parallel polarizer

b) Cross polarizer with $0 \mathrm{~V}$

c) Cross polarizer with $2500 \mathrm{~V}$.

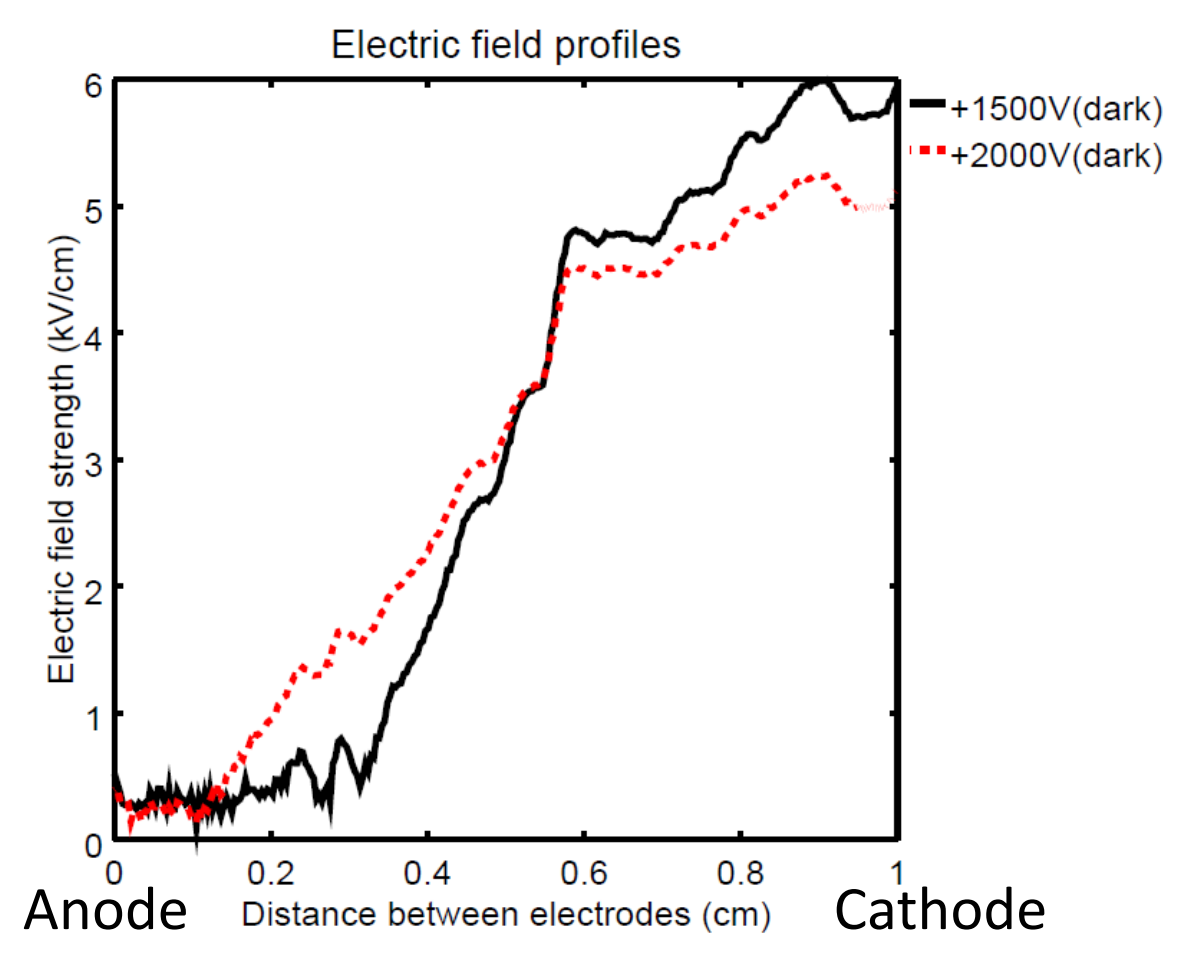

The detector dimensions: $4.4 \times 4.4 \times 10 \mathrm{~mm}^{3}$.

No residual stress was observed under the cross polarizer for all four VFG detectors fabricated. 


\section{Best CZTS virtual Frisch-grid detector}

Device response of the best virtual Frisch grid detector.
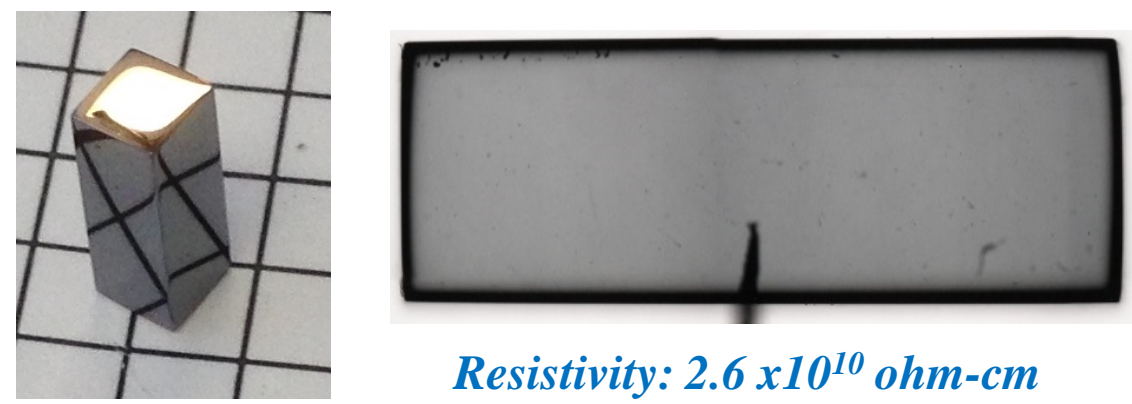

Resistivity: $2.6 \times 10^{10} \mathrm{ohm}-\mathrm{cm}$

Left: Picture of the detector: $3.6 \times 3.4 \times 9.7 \mathrm{~mm}^{3}$

Right: microscopic scan IR transmission image
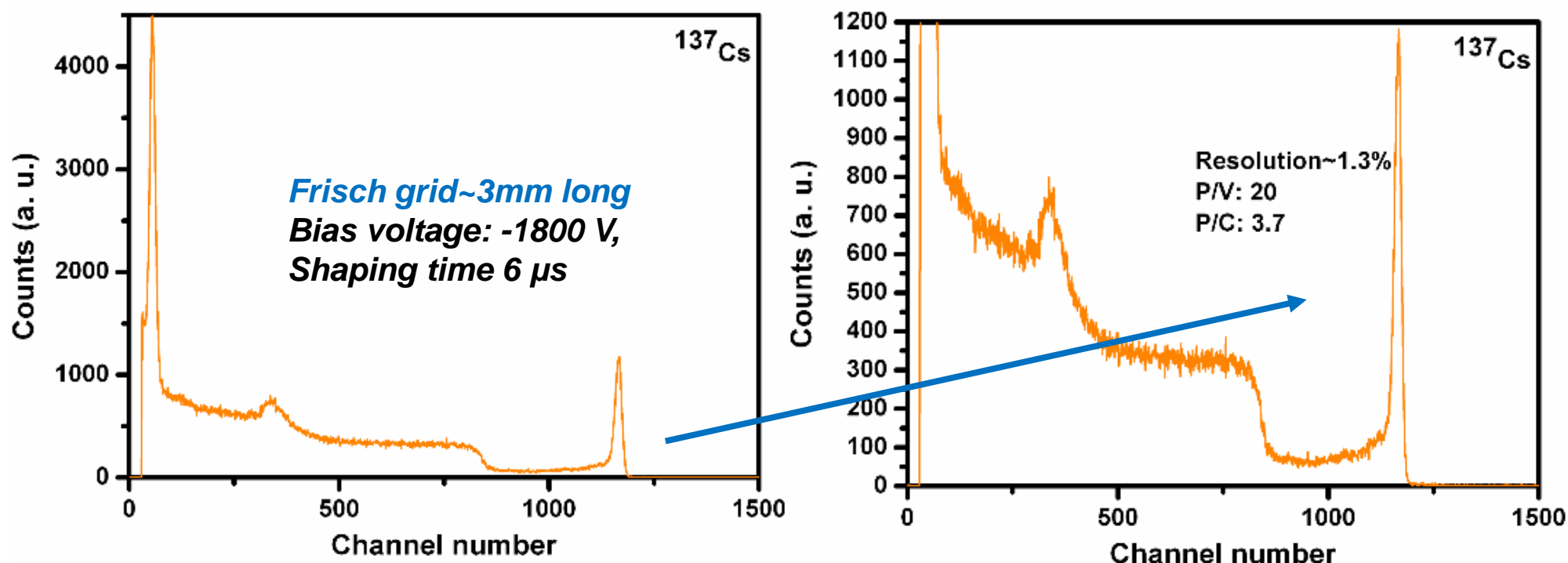

Bias voltage: 1800V, Shaping time 6 micro sec (Frisch grid $3 \mathrm{~mm}$ long)

\section{All the spectra are as-measured without any correction technique.}




\section{Best CZTS virtual Frisch-grid detector}

Device response of the best virtual Frisch grid detector.
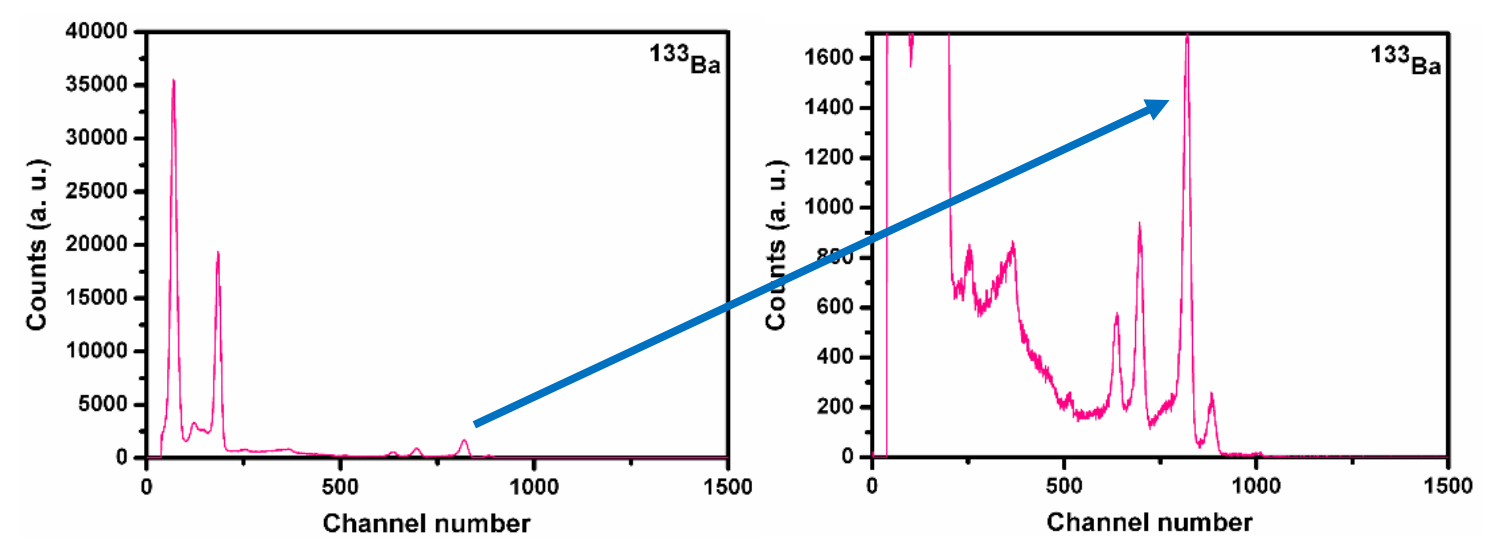

Bias voltage: $1800 \mathrm{~V}$, Shaping time 3 micro sec
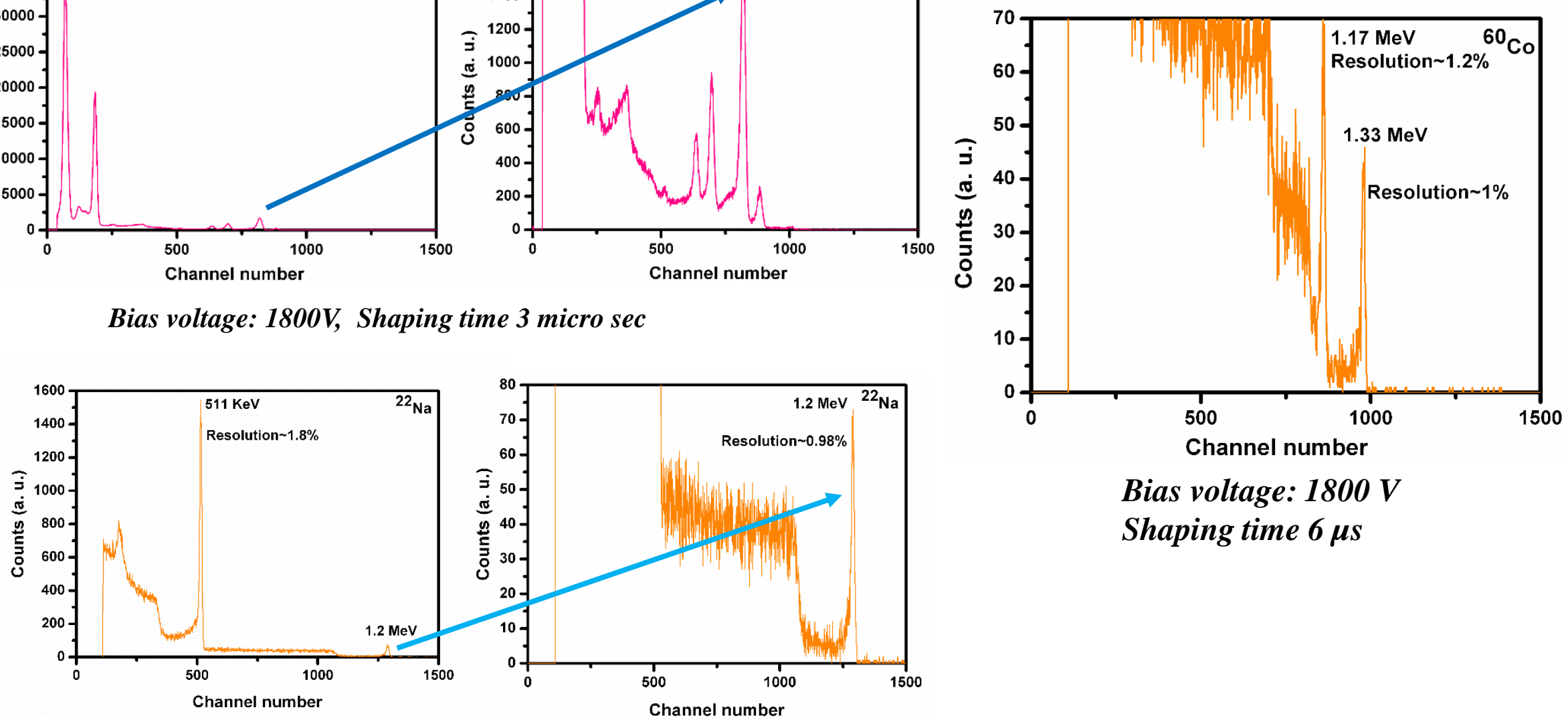

Bias voltage: $1800 \mathrm{~V}$, Shaping time $6 \mu \mathrm{s}$

All the spectra are as-measured without any correction technique. 
 \\ Unclassified}

Detector response of THM-grown

\section{U.S. DEPARTMENT OF $C d_{0.9} Z n_{0.1} T e_{0.98} S e_{0.02}$ at different shaping time}

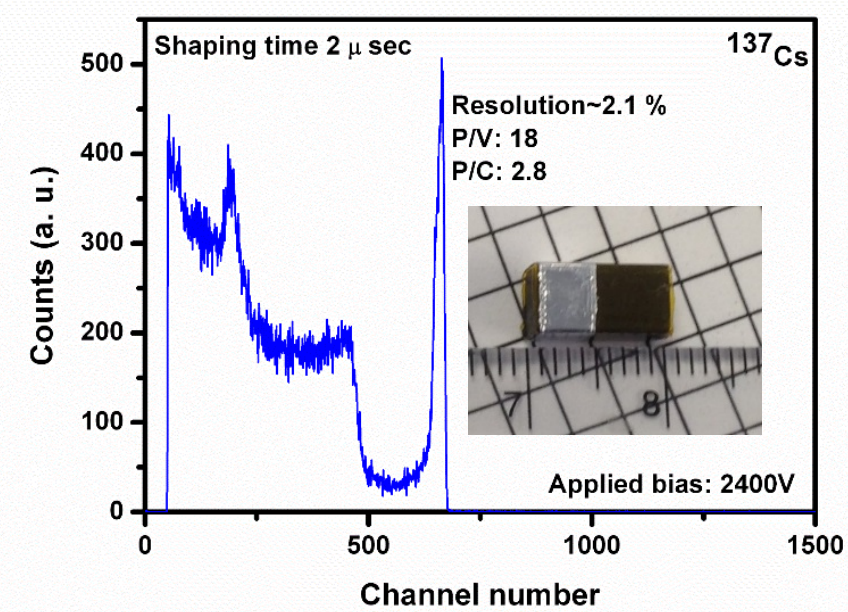

a

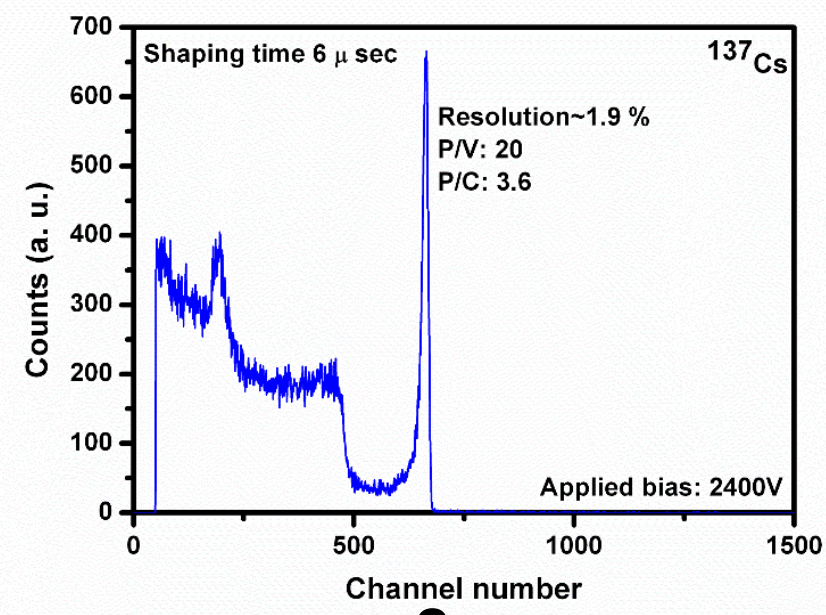

C

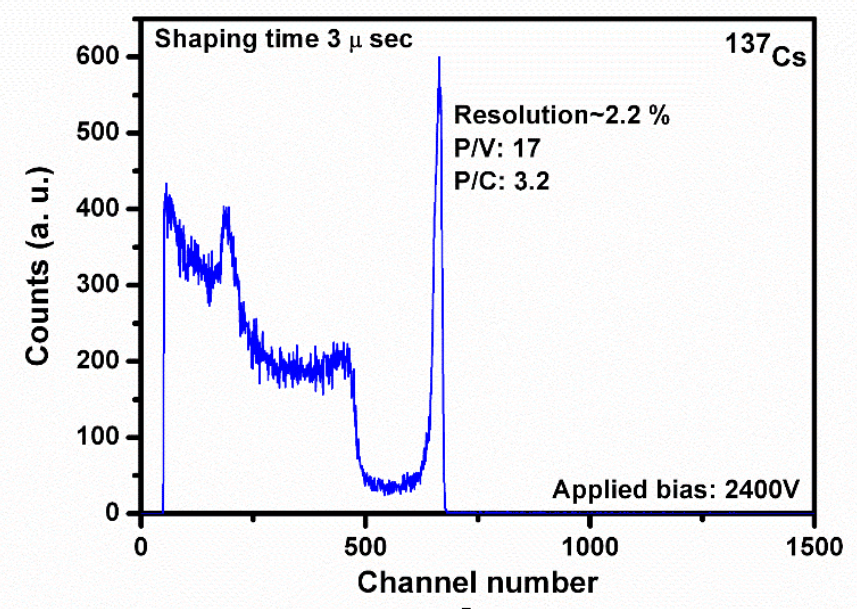

b

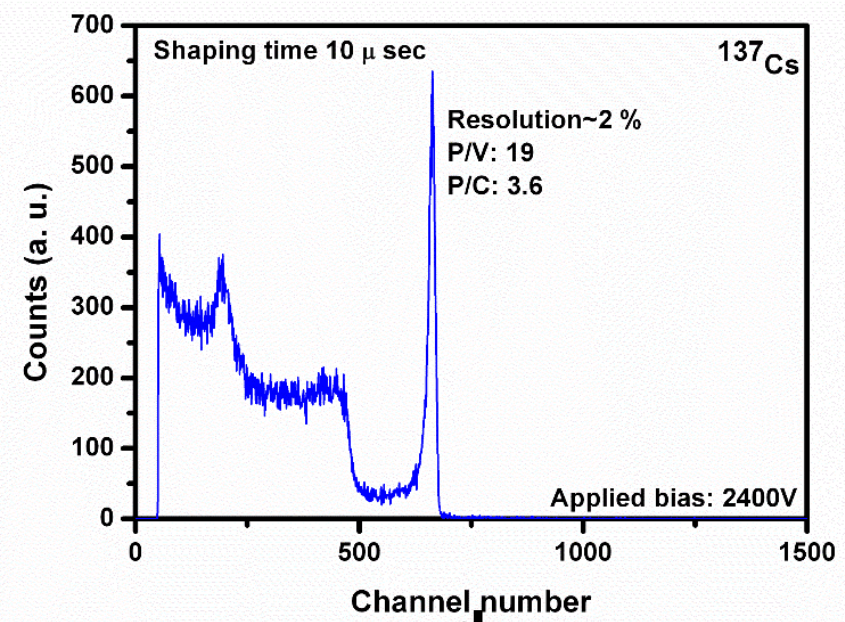

d

Response of VFG detector at different shaping time a) $2 \mu \mathrm{sec}$, b) $3 \mu \mathrm{sec}$, c) $6 \mu \mathrm{sec}$ and d) $10 \mu \mathrm{sec}$. The detector dimensions: $4.8 \times 4.9 \times 9.7 \mathrm{~mm}^{3}$. (Frisch grid 4mm long) 


\section{Detector quality at a glance}

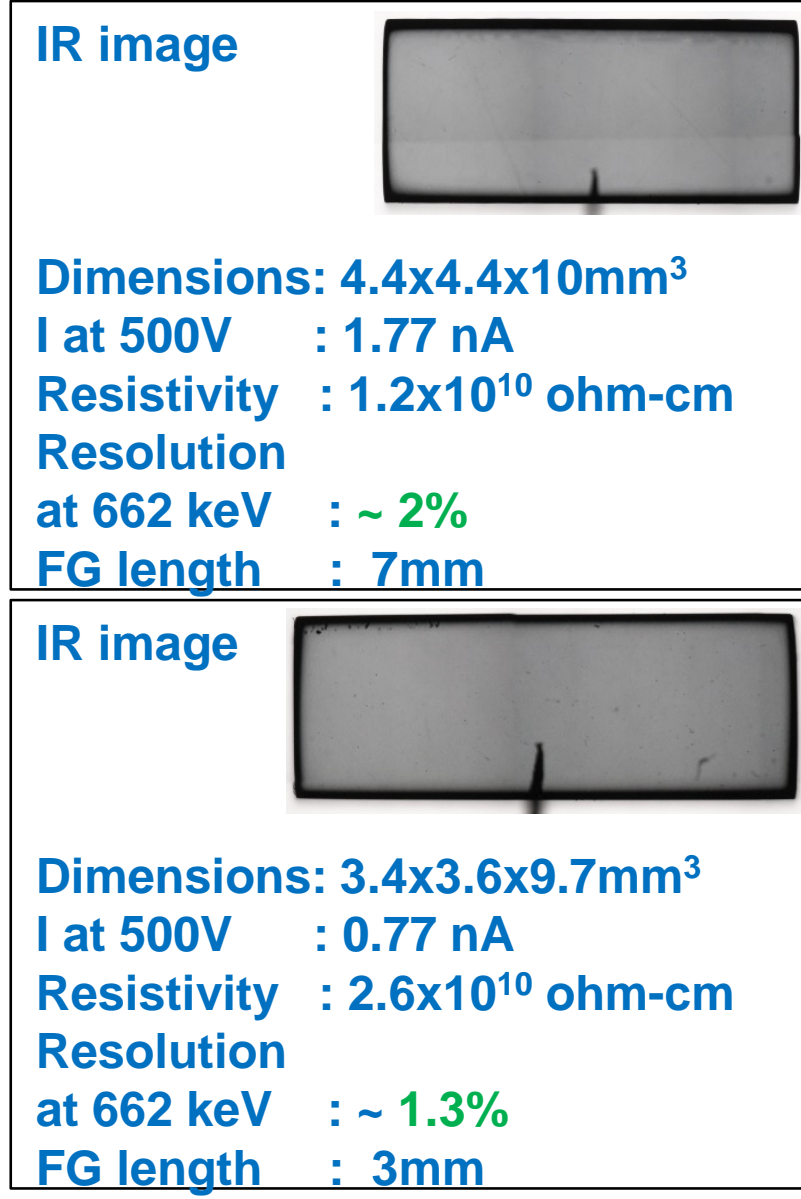

\begin{tabular}{|l|l|}
\hline IR image & \\
\cline { 2 - 2 } & \\
Dimensions: & $3.4 \times 3.4 \times 9.15 \mathrm{~mm}^{3}$ \\
I at 500V $\quad: 0.57 \mathrm{nA}$ \\
Resistivity & $: 1.5 \times 10^{10}$ ohm-cm \\
Resolution & \\
at $662 \mathrm{keV}$ & $: \sim 1.6 \%$ \\
FG length & $: 3 \mathrm{~mm}$ \\
\hline \hline IR image & \\
& \\
& \\
Dimensions: & $4.8 \times 4.9 \times 9.7 \mathrm{~mm}{ }^{3}$ \\
I at 500V & $: 1.26 \mathrm{nA}$ \\
Resistivity & $: 3 \times 10^{10}$ ohm-cm \\
Resolution & \\
at 662 keV & $: \sim 1.9 \%$ \\
FG length & $: 4 \mathrm{~mm}$ \\
\hline
\end{tabular}

Detector qualities are comparable to good quality CZT available today.

Quasi-hemispherical detector response:

Dimensions: $7.34 \times 6.35 \times 4.5 \mathrm{~mm}^{3}$ E-res. at $662 \mathrm{keV}: \sim 3 \%$

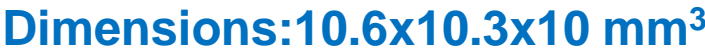
E-res, at $662 \mathrm{keV}: \sim 4.5 \%$

All the charge transport characteristics and the detector responses are performed on as-grown THM CZTS ingots. 


\section{Technical challenges and future work}

Technical Challenges

- Increase grain size of the ingots.

- Make special efforts to increase the resistivity up to $2 \times 10^{10} \mathrm{ohm}-\mathrm{cm}$ for THM grown $\mathrm{Cd}_{0.9} Z n_{0.1} \mathrm{Te}_{0.93} S e_{0.07}$ ingots.

Future Work

- We have optimized the growth parameters for seeded growth to get slightly convex interface. Seeded growth will be carried out for two inch THM growth.

- Characterization of the as-grown ingots will continue serving as feedback towards improving the material growth process.

- Fabrication of detectors larger than $1 \mathrm{~cm}^{3}$ with enhanced charge transport properties.

\section{Acknowledgments}

We thank the Office of Defense Nuclear Nonproliferation Research \& Development (DNN R\&D) for supporting this work. 


\section{UNCLASSIFIED}

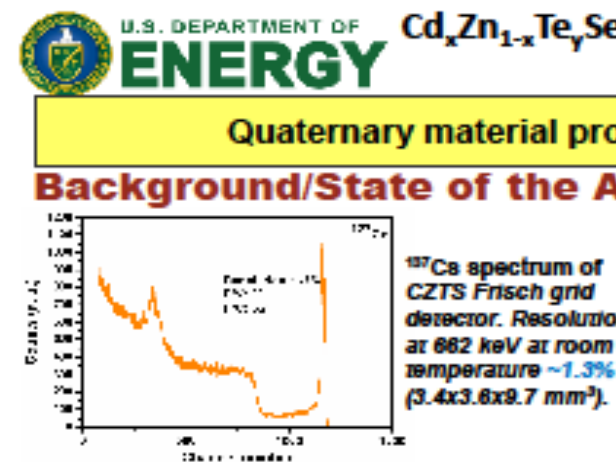

- Today. CZT is the most advanced roomtemperature semiconductor material for gamma-ray detection.

- However, it suffers from 3 major detrimental defects (non-unity segregation of $\mathrm{Zn}$, sub-grain boundary dislocation networks, and $\mathrm{Te}$ inclusions).

- These issues cause low yield and high cost of CZT radiation detectors, limiting their applications.

- Researchers have tried to solve the issues by improving the crystal growth process and postgrowth annealing). with limited success.

\section{Innovation}

\section{- Selenium in the CZT matrix was found} to be effective in arresting sub-grain boundary networks and producing compositional homogeneity and lower concentration of $\mathrm{Te}$ inclusions.

- All these defects have deleterious effects on $\mu \mathrm{r}$. Since we have drastically reduced these defects in CZTS, we believe that the $\mu \mathrm{r}$ values can be improved significantly compared to CZT.

- Thus CZTS has tremendous potential for the production of high-performance detectors at a substantially lower

Defense Nuclear Nonproliferation R\&D

\section{merging High-Performance Gamma-Ray Detector}

crystals with less strain and very high compositional uniformity

\section{Approach, Metrics and Outcomes}

\section{MAIN ACHIEVEMENT}

- The goal is to develop growth technology to produce CZTS radiation detectors better than today's large-volume CZT and at a lower price.

\section{HOW IT WORKS}

- By introducing Se in CZT material, we are able to use the Traveling Heater growth method (THM) to produce highquality CZTS crystals with uniform composition and reduced dislocation networks using THM growth. Comparison to Bridgman grown crystals is also being pursued.

- We are using modified THM growth at a lower temperature gradient compared to the conventional technique to produce detector-grade CZTS without requiring post-growth wafer annealing. which is needed for CZT.

-We are using first-principles theory to guide choice of ingot compositions for optimum bandgap and to characterize remaining deleterious defects to help improve resistivity.

- We achieved very high $\mu \mathrm{r}$ values within a very short period of research, as compared to CZT development.

\section{ASSUMPTIONS AND LIMITATIONS}

- The current results obtained in the short period of $\sim 5.5$ quarter (high $\mu$ r. 1.3\% resolution (as measured) for virtual Frisch grid detector at $662 \mathrm{keV}$ ) are very promising. We are optimistic to achieve the end goal upon completion of the project.

- The results achieved so far are highly encouraging and the detector performance is equivalent to high quality CZT presently available, indicate very low risk level and potentially high pay-off.

\section{UNCLASSIFIED}

Impact

- This project will result in a technology for producing a better room-temperature semiconductor detector at lower cost.

- The technology will allow gamma-ray detection with high energy resolution and high detection efficiency per unit volume.

- The technology is needed by federal agencies (DOE, DOD and DHS) and the IAEA for nuclear and radioactive material detection and imaging.

- Manufacturers of medical imaging devices will also be interested in this novel material to enhance the performance of their imaging devices and reduce the material cost.

TRLs: start at TRL2 and finish at TRL3

\section{Goals/Action Plan}

\section{Current FY}

- Produce 8 CZTS ingots \& fabricate high quality detectors.

- Compute electronic properties of native point defects across CZTS composition range.

Future FY

- Seeded growth of CZTS by THM

- Compute electronic properties of impurities and defect complexes in CZTS alloy to guide further improvements in resistivity and validate against experiments

\section{Team}

BNL, LLNL, and SRNL

Utpal N Roy

uroy@bnl.gov, phone \# 6313444168 